\title{
Seismic Safety Assessment of Historical Structures Using Updated Numerical Models: the Case of Mallorca Cathedral in Spain
}

\author{
Ahmed Elyamani ${ }^{1}$, Pere Roca ${ }^{2}$, Oriol Caselles ${ }^{3}$, and Jaime Clapes ${ }^{3}$ \\ ${ }^{1}$ Department of Archaeological Conservation, Faculty of Archaeology, Cairo University, Giza, Egypt \\ ${ }^{2}$ Department of Construction Engineering, Technical University of Catalonia, Barcelona, Spain \\ ${ }^{3}$ Department of Geotechnical Engineering and Geo-Sciences, Technical University of Catalonia, Barcelona, Spain
}

\begin{abstract}
The paper presents an integrated approach aimed at assessing the seismic safety of Mallorca cathedral. This cathedral is an extraordinary historical construction dating back to the middleages. The experimental modal parameters of the cathedral were identified using Ambient Vibration Testing (AVT). The cathedral numerical model was updated using the identified modal parameters. This updated model was then used to study the seismic response of the cathedral using non-linear static (pushover) analysis. A sensitively analysis was carried out to reveal the dependency of the seismic capacity on the input materials properties. To assess the seismic performance and the safety of the cathedral, the N2 method was employed. It was found that the cathedral is safe when subjected to the earthquakes expected in Mallorca Island.
\end{abstract}

\section{Key words}

Seismic assessment, Dynamic identification, Model updating, Pushover analysis, N2 method

\section{INTRODUCTION}

In the recent years a number of catastrophic earthquakes occurring in Europe resulted in significant damage to cultural heritage buildings. The damage observed in different types of structures after Lorca earthquake (Spain) in 11th May 2011 was discussed in several publications such as [1-8]. Brandonisio et al. and Lagomarsino [9-10] showed the effects of L'Aquila earthquake (Italy) occurred in 9th April 2009. Cattari et al. and Sorrentino et al. [11-12] discussed the performance of some types of structures affected by Emilia earthquake (Italy) occurred in May 2012. The Van earthquake that struck eastern Turkey in 23rd October 2011 and the related damage was discussed by [13-14].

Due to the large losses in invaluable historical structures due to earthquakes, modern societies are allocating great efforts to protect their culture heritage buildings from earthquakes. European researchers, in particular, have carried out a number of research projects on the subject and on closely related topics like in-situ investigation, structural monitoring and conservation of historical structures. Among them are [15-20]. 
This research was carried out within the research project NIKER [21] aimed at investigating the effects of earthquakes on historical constructions via extensive experimental and numerical studies and the application to several case studies. Mallorca cathedral has been chosen as one of the selected case studies. Due to the difficulties often faced when assessing the seismic safety of a historic structure, it is needed to combine different approaches in the assessment, such as historical investigation, inspection, experiments, monitoring and structural analysis. The aim is to respect the authenticity of the historic structure, to the extent possible, by designing an efficient solution which, while attaining the required safety target, minimizes the impact in terms of material and structural alteration. According to different international documents (ICOMOS/ISCARSAH Recommendations) and annex I of ISO 13822 standard [22], a minimum intervention is an intervention decided and designed so as to satisfy this requirement. Minimum interventions are based, for obvious reasons, on a deep knowledge of the structure, its possible problems and the effect that possible actions (including the earthquake) may have on it.

In the presented research, aimed to the seismic assessment of a large Gothic construction, the knowledge on the performance of the building was acquired by using, in an integrated way, structural analysis in combination with experimental tests. The experimental investigation included dynamic identification tests followed by the continuous dynamic monitoring. These investigations aimed at characterizing the modal parameters of the cathedral including the natural frequencies, the modes shapes and the damping ratios. A Finite Element (FE) model of the cathedral was updated to match the numerical natural frequencies and mode shapes with the experimental ones. Once updated, the model was used in the seismic assessment via the application of nonlinear static analysis. In addition, simplified limit analysis was employed to cross check the numerical results. The N2 method was used to characterize the seismic safety of the cathedral.

\section{MALLORCA CATHEDRAL}

\subsection{Description}

Mallorca cathedral is located in the city of Palma, Mallorca Island (Spain). It is a Gothic construction built from $14^{\text {th }}$ to $16^{\text {th }}$ centuries (Figure 1). The construction started around the year 1300. The Trinity Chapel ( $1^{\text {st }}$ part in the plan in Figure 2 ) was completed in year 1311 while the Royal Chapel ( $2^{\text {nd }}$ part in the plan in Figure 2 ) was finished around year 1370 . The imposing main large nave and the west facade $\left(3^{\text {rd }}\right.$ part in the plan in Figure 2$)$ were completed by the year 1601.

The main nave has a length of $77 \mathrm{~m}$ distributed over eight bays and the width covered by the naves is $35.3 \mathrm{~m}$, Figure 2. The lateral nave and the central nave spans are $8.75 \mathrm{~m}$ and $17.8 \mathrm{~m}$, respectively. The lateral naves are covered by pointed vaults of simple square plan, whereas in the central nave they are of double square plan.

This scheme is repeated in all the bays of the naves except in the $5^{\text {th }}$ one (from the choir), due to the presence of lateral doors. In this bay, the longitudinal span of the vaults is slightly 
longer. The height reached by the vaults at their highest point (the key of the transverse arches) is about $44 \mathrm{~m}$. The cathedral is also unique in being the Gothic cathedral with the highest lateral naves $(29.4 \mathrm{~m})$. All of the octagonal columns have a circumscribed diameter of $1.7 \mathrm{~m}$ except those of the first three bays from the choir that have a slightly lesser value of $1.6 \mathrm{~m}$. The tower and the two adjacent buttresses are noticed to be connected from the ground level up to a level of $17 \mathrm{~m}$. Above this level up to the buttress top, a narrow separation joint is noticed which suggest that the tower might not be connected to the buttresses from this level up (Figure 3). The uncertainty in the connection degree between the tower and the adjacent buttresses has an influence on the numerical model of the cathedral as will be discussed later.

The buttresses show a false window, in their lower part, built with a masonry wall whose thickness is inferior to the rest of buttress. Before a recent repair, several cracks could be identified in the perimeter of the false window showing that, in fact, the false window acted as a true weakness. In the FE models prepared (section 3.1), the false windows have been modelled as full openings.

When compared with other Gothic cathedrals, it is found that its piers show an unusually large slenderness ratio, while its main nave span is the second longest span among Gothic cathedrals after Girona cathedral. Its main nave is among the highest ones after those of Beauvais and Milan cathedrals. Since 1931, the cathedral is classified as Cultural Heritage of National Interest. More information on the cathedral and the previous studies carried out can be found in [23-28].

\subsection{Damage}

Cracking survey revealed presence of cracking and other damage in some of the structural elements of the cathedral [26, 29-30]. In some columns locally distributed vertical or oblique cracks are found. These cracks tend to concentrate close to the less confined parts of the section, i.e., the corners. Additionally, GPR and seismic tomography exploration of the columns has pointed out that some columns have minor inner defects [31]. Figure 4 reports the crack survey of the north and the south clerestory and exterior walls as can be seen from inside the cathedral. It must be noted that some of this damage has been repaired in recent restoration works. Pictures of these cracks are shown in Figure 5. It was noticed that all the bays of the clerestory walls were cracked. The first four bays from the west façade showed more intensive cracking pattern when compared to the bays near the east façade. The bay with the longest span exhibited more cracks than the other bays. Regarding the cracks shapes, two types could be noticed, the first were the diagonal cracks around the openings of the windows. The second were the vertical cracks between the walls and the supporting elements whether (columns or buttresses). The distribution of the diagonal cracks is similar to that of the damage predicted by the pushover analysis (discussed later in section 6.2.1), which suggest that it might be related to the seismic history of the island of Mallorca. Cracks also exist in other elements such buttresses and lateral nave vaults.

Deterioration and losing of mortar in mortar joints seems to have affected severely the cathedral in the past. Due to it, a large number of vaults of the main nave had to be repaired or reconstructed during the early 18th. For the same reason, the flying buttresses had to be entirely repaired or substituted also during the $18^{\text {th }} \mathrm{c}$. Continuous re-pointing of mortar joints has been carried out in the exterior walls and flying arches also after their reconstruction. The reason for 
the loss of mortar is attributed to the expansive recrystallization of salts migrated from the stone. In turn, the presence of salt in the stone was due to the fact that the original quarries were all at the seaside to allow for ship transportation to the cathedral.

\section{BRIEF ON SEISMICITY OF MALLORCA ISLAND}

The seismicity in Mallorca Island is low. The Spanish seismic data bank elaborated by the IGN [32] reported 21 events only in the period from 1654 to 1996, Figure 6. No data prior to 1654 are available [33]. Only three of those events had greater intensity than VI (MSK scale): Campos-Palma 1660, Selva 1721 and Palma-Marratxí 1851 [34], Figure 6. The Campos-Palma earthquake occurred on 18/3/1660 and had an intensity of VII with epicenter in the east of the Island. No damage to the buildings was reported due to this event. This event was followed by three aftershocks in 19, 26 and 28 of the same month [34-35]. The earthquake of Selva hit the Island in 24/3/1721 with intensity of VII resulted in the collapse of several houses [36]. The earthquake of Palma-Marratxí taking place in 15/5/1851 is the largest known one to have hit the Island with VIII intensity. It caused the collapse of several houses and resulted in severe damage in many towers that had to be demolished afterwards. Additionally, large cracks were noticed in Mallorca cathedral [36-37]. During the aftershock sequence, at least 13 earthquakes were felt [38] which resulted in the destruction of the previously damaged buildings and caused the total collapse of the Sant Marçal church [39].

In the 20th century, the seismic activity was lower than during $19^{\text {th }}$ century [33]. Discrete events took place in two well defined periods, from 1919 to 1923 and from 1995 to 1996. The first period was initiated by the V MSK Montuiri event [35], followed by two IV MSK events and terminated by a III MSK event. During the second period only II-III MSK intensities were produced by 3.3 to $2.6 \mathrm{Mb}$ shallow earthquakes at recurrent sites such as Campos [33]. The seismic events since 1970 offered reliable focal parameters [33]. This instrumental records show that the inland seismicity is characterized for being shallow $(<10 \mathrm{~km} \mathrm{depth})$ and of low magnitude $(<3.5 \mathrm{Mb}$ ). Moderate earthquakes of up to $4.3 \mathrm{Mb}$ occurred in neighboring offshore localities in the Valencia trough [33].

\section{AMBIENT VIBRATION TESTING (AVT)}

The objective of AVT was to identify the natural frequencies, mode shapes and damping ratios of the cathedral. The first two parameters were used for the FE model updating. A brief about the identification process is given here and full details can be consulted at $[23,40]$.

Three tri-axial force balance accelerometers were used to carry out the tests. The tests configuration was based on a preliminary modal analysis carried out using an initial FE model of the cathedral. It was noticed that only the modes number 1 (Figure 7-a) and 2 (Figure 8-a) were global ones with considerable mass participation and characterized by predominant movement of the main and lateral naves of the cathedral. Therefore, the sensors were organized so that capturing these two modes would be achievable, Figure 9. 
The dynamic identification was carried out using multiple methods implemented in [41] using four methods: the Frequency Domain Decomposition (FDD) [42]; reference-based covariance-driven Stochastic Subspace Identification (SSI-cov/ref) [43]; reference-based datadriven Stochastic Subspace Identification (SSI-data/ref) [43] and poly-reference Least Squares Complex Frequency domain identification (pLSCF) [44].

Each setup was processed individually, and the modes that appeared within each setup were selected. It was found that in each setup some modes appeared clearly while others were difficult to recognize. Accordingly, this post processing step helped in selecting the accurate combination of setups that would give the best estimation of the modal parameters for any mode. Those setups are called hereinafter "selected setups".

Table 1 reports the judgment of the identified modal parameters of the cathedral. The global modes number 2,3 and 4 were the best estimated ones because from all methods whether considering all setups or selected setups they had very near modal parameters. These modes were global ones with high mass participation, which made their identification more attainable than in the case of more local ones, Figures 3-b and 4-b. For the remaining modes, only their natural frequencies were satisfactory identified and the remaining modal parameters were poorly identified.

The AVT was followed by a continuous monitoring system. The system was composed of a digitizer, a Data Acquisition system (DAQ), a Global Positioning System (GPS) antenna, an internet router and the three tri-axial accelerometers previously used in the dynamic identification tests. Two of the accelerometers were placed at points P16 and P6. The third one was placed on the ground near to the third north buttress from the west façade. The system was adequately programmed to continuously measure, record, and wirelessly transfer the records of the accelerations during a long period of time, on a $24 \mathrm{~h}$ basis, without having to set up an activating threshold. It was decided to implement this type of monitoring because, as mentioned, the amplitude of the seismic motion expected in the island of Mallorca is low to moderate and may be similar in magnitude to frequent wind effects. The sampling frequency was 100 samples per second.

\section{MODEL UPDATING}

\subsection{Description of the initial FE model}

The meshing was performed using GID software [45] then it was processed using Diana code [46]. The different parts of the cathedral were modeled using TE12L solid elements consisting of four-node three-side isoparametric solid pyramid, Figure 10. These elements represented approximately $95 \%$ of the mesh. The remaining $5 \%$ represented the vaults of the apse were modeled using T15SH elements, three-node triangular curved shells. At the base, the three components of the displacement were restrained. The model included 149248 nodes and 491851 elements with total of 490789 degrees of freedom. Among the materials that compose the building, four characteristic materials were considered in the model. The corresponding properties are summarized in Table 2 . These properties were decided on the base of experimental 
evidence gathered during the study of the building, including laboratory tests on stone cylindrical samples taken from the structure or from the original stone quarries. The masonry properties were estimated based on the stone determined values and the knowledge on the masonry morphologies.

Not all parts of the cathedral were modeled. The lateral chapels' vaults and the longitudinal wall connecting all the buttresses were initially not modeled for the sake of simplification as they were initially deemed not important for a global description of the dynamic response of the cathedral. Further analysis, however, showed that in spite of their secondary character, these elements were meaningful for an accurate description of the dynamic response of the structure as will be discussed later.

\subsection{Initial correlation of experimental and numerical modal parameters}

The experimental mode shapes and natural frequencies obtained from the dynamic identification tests and their numerical counterparts were compared using the Modal Assurance Criteria (MAC) [47] and the frequency discrepancy $\left(\mathrm{D}_{\mathrm{f}}\right)$ [48], defined as:

$M A C=\frac{\left|\sum_{i=1}^{n} \varphi_{i}^{e} \varphi_{i}^{n}\right|^{2}}{\sum_{i=1}^{n}\left(\varphi_{i}^{e}\right)^{2} \sum_{i=1}^{n}\left(\varphi_{i}^{n}\right)^{2}}$

Equation 1

where: $\varphi_{i}^{e}$ is the experimental mode shape vector and $\varphi_{i}^{n}$ is the numerical mode shape vector.

$D_{f}(\%)=100\left|\frac{f_{i}^{e}-f_{i}^{n}}{f_{i}^{e}}\right|$

Equation 2

where: $f_{i}^{e}$ is the experimental frequency and $f_{i}^{n}$ is the numerical frequency

In Table 3 the best correlated pair of numerical-experimental modes and the corresponding $\mathrm{D}_{\mathrm{f}}$ and MAC values are shown. The two experimental mode shapes that were estimated to a good level of accuracy, i.e., modes 2 and 4 have good MAC values 0,89 and 0,74 respectively. The low MAC values obtained for other modes can be explained because of the difficulty of identifying the corresponding experimental mode shapes. For all modes, except first one, the values of $D_{f}$ were very low which showed the good distribution of masses and stiffness in the FE model. However, for the numerical mode 1, which was a global longitudinal one, the high $\mathrm{D}_{\mathrm{f}}$ value (11\%) suggested that in the longitudinal direction of the cathedral, the real stiffness was larger than that simulated by the model.

\subsection{Model updating philosophy}

The dynamic identification tests were oriented to capture the global behavior of the cathedral. There were two modes that represented this behavior and were accurately identified. Those were the 1st numerical associated with the 2nd experimental (1Num-2Exp) which was a pure longitudinal mode, and the 2nd numerical associated with the 4th experimental (2Num4Exp) which was a transversal mode, Figures 3 and 4. Consequently, the updating process could be uncoupled so that the 1Num-2Exp mode and the 2Num-4Exp modes could be used to adjust the model in the longitudinal and the transversal directions, respectively. For these modes, Figure 
11 compares the experimental and the numerical normalized modal displacements in the $\mathrm{X}$ (transversal), $Y$ (longitudinal) and Z (vertical) directions at each AVT measurement point for the three zones of the cathedral—corresponding to the south, central and north naves.

This comparison allowed a better understanding of the correlation between the experimental and the numerical mode shapes and helped in showing the parts of the FE model that needed updating. As can be noticed in Figure 11, from the plot of 1Num-2Exp mode, it appeared that the numerical-experimental correlation was good for the $\mathrm{Y}$ and $\mathrm{Z}$ directions.

Instead, for the X direction, the model was not well matched with AVT. This finding, in addition to the high difference between the numerical and experimental frequencies previously pointed out (with $\mathrm{Df}=11 \%$ ) raised the need for an updating by adding the missed walls that connected the buttresses. As a consequence, the numerical frequency might increase and became closer to the experimental one. Finally, there is a major crack between the third and the fourth bays that might as well influence on the dynamic response in the longitudinal direction.

For the 2Num-4Exp mode, it was possible to note that the north nave showed the lowest correlation in the transversal $\mathrm{Y}$ direction. Therefore, it was worth trying to connect the tower with the adjacent buttresses and see the effect. Connecting the tower with the full height of the buttresses might increase the stiffness in the transversal direction. In the cathedral's structural configuration the buttresses were the main elements providing stiffness in the transversal direction. Similarly, the modulus of elasticity of the masonry of the buttresses may have significant influence on this mode shape. Next, the discussion of the updating process is limited to the modal parameters that were satisfactory experimentally identified, i.e. the frequencies of all modes and the mode shapes of the modes 1Num-2Exp and 2Num-4Exp.

\subsection{Model updating results}

\subsubsection{Step 1: adding the longitudinal wall}

The longitudinal wall connecting all the buttresses was added to the model. It was found that the cathedral stiffness increased and therefore all the modes' frequencies increased, Table 4. Successfully, the Df of the 1Num-2Exp mode was decreased from $11 \%$ to 6,8\%. For the rest of the modes, the Df increased. Adding the wall was not so influential on the shapes of any of the first two modes and no significant changes were noticed in the MAC values.

\subsubsection{Step 2: considering the lateral chapels' vaults}

The chapel vaults were modelled as an equivalent system of springs with an equivalent stiffness. This stiffness was lately adjusted, within reasonable limits, in order to improve the matching with the experimental frequencies and modal shapes. In Table 4 the $\mathrm{D}_{\mathrm{f}}$ and MAC values of all modes are shown. As seen, the $D_{f}$ of the mode 1 Num-2Exp was reduced significantly from that of the previous updating step. However, the $D_{f}$ of the rest of the modes also increased. Negligible changes in the MAC values of all modes were noticed.

\subsubsection{Step 3: modifying the tower-cathedral connection}

As mentioned before, the tower was connected to the full height of the adjacent buttresses .The new connection did not reduce the north nave modal displacement. No improvement in the MAC value of the $2 \mathrm{Num}$ - $4 \mathrm{Exp}$ mode, but on the contrary, the frequency 
increased to $1,726 \mathrm{~Hz}$ which became more far than the experimental one. An increase in Df for all modes was also noticed. Thus, this model tuning was not considered and the tower-cathedral connection returned to its original.

\subsubsection{Step 4: adjusting the elasticity modulus of the buttresses}

In this trial a gradual reduction in the modulus of elasticity of the buttresses was carried out from $95 \%$ to $70 \%$ of the original value. In Figure 12, the relation between the used reduction factor and the Df of all the modes is shown. As can be noticed, reducing the modulus of elasticity of the buttresses resulted in reducing the Df for all the modes, except for the mode 1Num-2Exp. The reduction factor of $75 \%$ was considered as an optimized value. For this value, four out of the six modes had low Df values between 0,5 and 2,1 and the other two modes had Df values of 6,4 and 10,9 as summarized in Table 4. Negligible changes were noticed in the MAC values for all the modes.

\subsubsection{Step 5: Using elastic foundations}

The foundations were modeled using elastic springs in the vertical direction $(Z)$ and in the horizontal directions ( $\mathrm{X}$ and $\mathrm{Y}$ ). The horizontal stiffness of any spring was assumed equal in the $\mathrm{X}$ and $\mathrm{Y}$ directions and was taken as a ratio from the spring vertical stiffness. Most of the cathedral foundations were built on conglomerate rock and only a few of them were built on filling [49-50]. Therefore, two groups of springs were used, the first one represented the foundations on rock and the second one represented the foundations on filling.

The initial vertical stiffness of any spring assigned to any node at the cathedral base was calculated as the product of the soil modulus of subgrade reaction and the tributary area of the node. The modulus of subgrade reactions were taken as $1 \mathrm{E} 10 \mathrm{~N} / \mathrm{m}^{3}$ for the rock and $1 \mathrm{E} 7 \mathrm{~N} / \mathrm{m}^{3}$ for the filling, guided by the recommendations given in the soil investigation report of the cathedral site. The initial average vertical spring stiffness in the rock zone was $6,89 \mathrm{E} 9 \mathrm{~N} / \mathrm{m}$ and in the filling zone was 5,51E6 N/m. The horizontal stiffness of any spring was taken initially as $10 \%$ of the vertical stiffness.

In the updating process, three variables were changed, namely: (1) the vertical stiffness of the springs defined for the rock zone, (2) the vertical stiffness of the springs defined for the filling zone, (3) the ratio between the horizontal and the vertical spring stiffness. It should be noted that when changing a variable the other two variables were kept constant. It was noticed that the second variable was the one having a more pronounced influence on the dynamic behavior. As can be noticed in Figure 13, when using the initial value of this variable, and for all modes, the $\mathrm{D}_{\mathrm{f}}$ values increased significantly and the MAC values decreased significantly because of excess flexibility at the filling zone. When increasing it with two orders of magnitude, the $\mathrm{D}_{\mathrm{f}}$ values improved for almost all the modes and the MAC values retrieved the values of the previous updating step.

For the first variable, increasing the initial value with two orders of magnitude, improved slightly the Df values. For the last variable when using values more than $10 \%$, no changes occurred in the Df and MAC values for all modes. Summarizing, the best values for the average spring stiffness were $6,89 \mathrm{E} 11 \mathrm{~N} / \mathrm{m}$ and 5,51E8 N/m in the rock and the filling zones, respectively. The optimal horizontal stiffness was $10 \%$ of the vertical stiffness for any spring in the two zones. Table 4 reports the matching after adjusting the elastic foundations. As can be 
noticed, all the frequencies slightly decreased from the previous updating step and this improved the matching, in particular, for modes 2Num-4Exp and 5Num-5Exp.

\subsubsection{Step 6: damage simulation}

The last updating trial was to simulate the damage experienced by the cathedral. Among the most significant damage was the cracking that can be seen in many places. One of the significant cracks is the one located between the third arch and the fourth vault from the west façade, Figure 14. It was previously monitored for a period of about five years and proved to be active with a rate of $1 \mathrm{~cm} /$ century [26]. The static monitoring system aimed at measuring the crack widths, the tilts and the distance variations (openings) at some critical positions in the cathedral, in addition to measuring the environmental actions of the temperature, the humidity and the wind. The cracks were monitored at three columns, two locations at the upper south clerestory wall and two vaults. Base line extensometers were implemented to measure the opening of selected arches and vaults, at the level of their springing. The tilts were monitored at two positions, one of them aimed at measuring the tilt of the west facade.

To simulate the crack in the numerical model, a separation between the arch and the vault was made by doubling the nodes located at their contact line. This modeling approach allowed the reproduction of the crack effect for the first two numerical modes. Due to the large size of the model, this local crack did not show any significant effect neither on the natural frequencies nor on the mode shapes. The same values for $\mathrm{D}_{\mathrm{f}}$ and MAC of the previous updating step were obtained with the cracked model.

\subsection{Final FE model after updating}

The model of step 5 above was considered as the final one, Table 4. Comparing with AVT frequencies, the final model showed good Df values around $2 \%$ or less for four out of the six modes. Three from these four modes were global modes; those are: 1Num-2Exp; 2Num-4Exp and 10Num-8Exp. The two modes that exhibit relatively high Df values were local ones. This in turn showed the good ability of the model to reproduce the real global dynamic behavior of the cathedral. Regarding the MAC values, the two reliable experimental modes number 2 and 4 were in good correlation with their numerical counterpart number 1 and 4 with MAC values of 0,89 and 0,75 respectively. The MAC values for other modes were not significant because of their poor experimental identification.

Figure 15 compares the experimental frequencies and the frequencies of the initial and the final models. It can be noticed for the first two modes that negligible changes occurred in the MAC values. For the initial model, the frequencies of five modes were very near to the experimental frequencies (their dots laid on the $45^{\circ}$ line). For the final model, the frequencies of four modes laid on the $45^{\circ}$ line. The important gain from updating the initial model is in the reduction of the $\mathrm{D}_{\mathrm{f}}$ of the first mode from $11,0 \%$ to only $1,9 \%$ while keeping the same MAC value. This mode was the one with the highest mass participation factor among all modes (about $60 \%$ in longitudinal direction). 


\section{SEISMIC ASSESSMENT}

Nonlinear static (pushover) analysis was carried out to assess the seismic safety of the cathedral. To reveal the dependency of results on the input material properties, a sensitivity analysis was performed. Then, the numerical results were compared with the results of the kinematic limit analysis as a way to cross check the seismic safety assessment. For evaluation of the seismic performance of the cathedral, the N2 method was employed.

\subsection{Constitutive model and properties of materials}

To simulate the nonlinear behavior of the masonry, tensile regime was modeled using smeared cracking, in specific, multi-directional fixed crack model. In this model cracking was specified as a combination of tension cut-off (Figure 16-a), tension softening (Figure 16-b), and shear retention. Compressive regime was modeled using isotropic plastic Drucker-Prager model. Table 5 lists the used properties of materials not mentioned in Table 2 above. The compressive strength $f_{c}$ of the first three materials were taken as found by [52] who carried out compressive tests on samples of the stone. For the filling material a low compressive strength was assumed. For all the materials, the tensile strength $\mathrm{f}_{\mathrm{t}}$ was assumed as $5 \%$ of $\mathrm{fc}$, the shear retention factor was taken as 0,01 and the two angles of internal friction and dilatancy were assumed equal (associated plasticity) with a value of $10^{\circ}$. Those values were reasonably assumed based on studies on similar historical construction [52-56].

The values of the ultimate crack strain $\varepsilon_{u}^{c r}$ were assumed so that the four materials had near tensile fracture energies. $\varepsilon_{u}^{c r}$ is related to the fracture energy $\mathrm{G}_{\mathrm{f}}$ by the following relation [46]:

$$
\varepsilon_{u}^{c r}=\frac{2 G_{f}}{f_{t} h}
$$

Equation 3

Where $h$ is the crack bandwidth taken as the cubic root of the element volume and $f_{t}$ is the masonry tensile strength.

\subsection{Nonlinear static analysis}

A monotonically increasing horizontal load was applied under constant gravity load. The adopted horizontal load distribution was a uniform load proportional to the structural elements' masses. The cathedral was subjected to the seismic loads in the longitudinal $(\mathrm{X})$ and the transversal (Y) directions considering both the positive and the negative sings. In the transversal direction, the structure resisted seismic loads thanks to the stiffness of the eight frame-like structures composed by the piers, the diaphragmatic arches, the flying arches and the buttresses; the west façade and the stiff walls at the apse area. These frames showed large capacity when the forces were applied in its more resistant (in plane) direction. In the longitudinal direction, the loading of the buttresses and the façade occurred in the direction perpendicular to their plane therefore causing a lower seismic global capacity.

For plotting a representative capacity curve of the structure, four control points were selected to represent the more realistic capacity. These points were: (1) the center of gravity of the full cathedral (CG-cathedral), (2) the center of gravity of the naves' roof (CG-roof), (3) the 
point with the highest elevation (Top) which located at the top of the gable of the west facade, and (4) the point with the maximum displacement (Max-D) in the direction under consideration.

\subsubsection{The seismic response in the longitudinal $( \pm X)$ direction}

The obtained capacity curve for the analysis in $+X$ direction is presented in Figure 17 . The point Top was found to be also the one with the highest displacement. From the capacity curve, it was observed that the behavior was linear up to a load value of about $0,040 \mathrm{~g}$ and the collapse occurred at $0,114 \mathrm{~g}$. Four different points on the curve are points (a) to (d) are selected to follow the collapse progression.

Damage starts to appear at about $0,04 \mathrm{~g}$ in the first bay of the upper and the lower clerestory walls due to the activation of the west façade overturning (Figure 18-a). The cracks are diagonal and initiate from the top of the windows' openings. At $0,07 \mathrm{~g}$, the first bay of the upper clerestory walls is totally damaged above the windows' openings (Figure 18-b), so that the west façade losses part of its effective connection to the nave. Damage also starts to develop in all the bays at the lower clerestory walls. The bay with the largest span (fourth bay from the west façade) shows more intense damage.

The damage observed in the previous loading stage experiences significant further development more at $0,091 \mathrm{~g}$ (Figure 18-c). The separation of the west façade with respet to ne nave increases due additional damage in the clerestory and exterior walls. The columns start to experience damage at their connection with the upper clerestory walls. At collapse (Figure 18-d) the west façade completely losses its connections with the rest of the cathedral.

The $-\mathrm{X}$ direction showed the lowest capacity among the four considered directions. The attained capacity was only 0,095g. Figure 19 shows the different capacity curves for the considered control points. The point Max-D was observed to be at the top of the most north buttress. The cracking process started like the case of $+X$ at about $0,04 \mathrm{~g}$. At $0,095 \mathrm{~g}$ the collapse occurred due to the overturning of the east façade after separation from the rest of the cathedral. The lower clerestory walls were diagonally cracked above and below windows' openings. The same was noticed for the first and the last bays of the upper clerestory walls. After being cracked at their top, the columns lost their connections with the upper clerestory walls.

\subsubsection{The seismic response in the longitudinal $( \pm Y)$ direction}

In the $+Y$ direction the cathedral showed a higher capacity $(0,118 \mathrm{~g})$ than that in the longitudinal direction. Figure 20 shows the capacity curves. The point Max-D was found to be at the top of the fifth flying arch counting from the west façade. As expected in masonry structures composed of arches, a series of disconnections (hinges) between structural parts could be noticed with the increase in the applied lateral load until reaching collapse. This process of cracking is shown in Figure 21. The hinge mechanism process started at a seismic load of $0,075 \mathrm{~g}$ (crack 1) with the arising of four cracks at the top of the column, the upper flying arch, the top of the lateral nave's vault and the connection of the buttress with the longitudinal wall, being the largest damaged area at the flying arch. The following group of cracks started at $0,093 \mathrm{~g}$ (crack 2) at the top of the lower flying arch, the bottom of the lateral nave's vault and the base of the buttress. One crack only initiated at $0,099 \mathrm{~g}$ (crack 3) at the bottom of the lower north flying arch. At $0,102 \mathrm{~g}$ a new crack appeared (crack 4) in the main nave vault followed by another one at the base of the buttress at $0,104 \mathrm{~g}$ (crack 5). The followed crack initiated at $0,106 \mathrm{~g}$ (crack 6) at the top of the vault of the north lateral nave. Four cracks opened at the load factor of $0,109 \mathrm{~g}$ (crack 
7), two at the north part of the bay, in specific, at the bottom of the upper flying arch and the connection of the lower flying arch with the main nave vault, the other two were at the south part at the connection of the lower flying arch with the main nave vault and just below the buttress window. Very near to collapse, at $0,114 \mathrm{~g}$, the base of the column was cracked (crack 8).

Regarding the crack in the buttress bottom, it should be noted that it does not meet the buttress false window due to the large influence of the stiffness and strength of the longitudinal wall, which largely affects to the distribution of damage in this region of the buttress.

In $-Y$ direction the resistance was the highest among all directions as can be seen in the capacity curve (Figure 22). In this figure the point Max-D was located at the top of the northern flying arch of the east façade. The capacity was $0,141 \mathrm{~g}$ which was about $20 \%$ more than $+\mathrm{Y}$ direction. The existence of the tower as a strong support near the middle of the structure was the reason for the higher capacity. Comparing this case with the previous case of $+Y$, it was noticed that a near sequence of structural elements' cracking was found. At first, the top of the column, the upper battery of flying arches, the extrados of lateral nave's vaults and the base of the buttress, and at last, the bases of the columns and the buttresses. In between, the lower battery of the flying arches, the extrados and the intrados of the lateral naves' vault cracked. An important difference between the two cases was the capability of the typical bay to resist after the initiation of the first crack in the case of $-\mathrm{Y}$ over a wider range of seismic loads from $0,094 \mathrm{~g}$ to $0,135 \mathrm{~g}$. The collapse occurred at $0,141 \mathrm{~g}$, whereas in the case of $+\mathrm{Y}$, a rapid cracking took place in a narrow range from $0,099 \mathrm{~g}$ to $0,114 \mathrm{~g}$ as previously mentioned.

\subsubsection{Sensitivity analysis}

A sensitivity analysis was carried out by varying the parameters that mostly influenced the behavior with the objective to investigate their effect on the seismic response of the cathedral. The values of the different mechanical properties of the defined materials in the FE model were changed and the new obtained capacities were compared with the reference model previously discussed. Due to the large size of the FE model and the required long computational time and hard drive storage capacity, only the weakest direction $-\mathrm{X}$ was evaluated. In each trial only one parameter was changed keeping all the other parameters constant. Table 6 summarizes the tried values in the parametric study. When presenting the capacity curves, the control point Max-D was used.

\subsubsection{Tensile strength}

As can be noticed in Figure 23 (left), a remarkable change in the capacity was associated with the change of the tensile strength. A reduction of about $24 \%$ was obtained when reducing the strength to the half of its reference value. An increase of about $23 \%$ was obtained when increasing the strength to the double of its reference value. Within the examined values, a linear trend between tensile strength and capacity could be noticed (Figure 23, right). Since the collapse was governed by the tensile cracking, this result was expected. For the examined values, the change in final displacement was not significant and the collapse mechanism remained the same.

\subsubsection{Compressive strength}

The effect of decreasing this strength property was more pronounced than increasing it. As shown in Figure 24 (left), when using $75 \%$ of the reference compressive strength, the capacity decreased by $23 \%$ and the final displacement decreased to about $50 \%$ of its reference value. Compared with the reference case, decreasing the compressive strength leaded the structure to 
suffer from higher ratio of stress/strength, so when applying the seismic load afterwards, the structure had less capacity to sustain it. In the same figure, it can be noticed that when increasing the compressive strength to the double of its reference value the capacity increased by only $6 \%$ with minor increase in final displacement. Since the collapse was not governed by the compressive failure, no benefit in strength was observed by increasing the compressive strengths. Figure 24 (right) presents the relation between the investigated ratios of $f_{c}$ and the attained capacity. There was stability in the attained capacity when increasing the ratio from 1 to 2 . This horizontal branch of the curve is expected to continue with higher ratios indicating the minor effect of increasing the compressive strength.

\subsubsection{Ultimate crack strain}

Figure 25 (left) shows the obtained capacity curves when varying the ultimate crack strain. It can be seen that reducing this parameter by one order of magnitude resulted in a significant reduction in the capacity (about 60\%) and the behavior was brittle. On the other side, the increase by one to three orders of magnitudes had slight influence on the capacity with an increase of about $4 \%$ only because increasing the ultimate crack strain leaded the material behavior to be like an elastic-perfect plastic behavior and no gain in the capacity was found Figure 25(right).

\subsubsection{Modulus of elasticity (E)}

Two values of the elastic modulus were examined: E/2 and E/4. Reductions in the capacity about $17 \%$ and $37 \%$ were found when reducing $\mathrm{E}$ to one half and one quarter of its reference value, respectively, Figure 26. In addition, the nonlinear behavior started earlier when reducing E. In the reference case it started at about $0,04 \mathrm{~g}$, while it starts for less than $0,03 \mathrm{~g}$ at $\mathrm{E} / 2$ and for about $0,02 \mathrm{~g}$ for $\mathrm{E} / 4$. The influence of $\mathrm{E}$ is attributed to the nonlinear geometric effects linked to the slenderness of the piers and other members of the structure.

\subsection{Kinematic limit analysis}

Based on the collapse mechanisms found in the longitudinal direction by the pushover analysis, two collapse mechanisms were studied by the kinematic limit analysis technique. For the $+X$ direction, the west façade overturning was considered. For the $-X$ direction, the west façade overturning was considered. The found capacities were $0,144 \mathrm{~g}$ and $0,118 \mathrm{~g}$ for the $+\mathrm{X}$ and $-\mathrm{X}$ directions, respectively. Those values were near to the capacities obtained by the pushover analysis. Detailed calculations can be checked at [23].

\subsection{Seismic performance evaluation}

\subsubsection{Characterization of the seismic demand}

The seismic demand was characterized using two codes: the Spanish code for seismic design (NCSE-02) [57] and the Eurocode 8 (EC-08) [58]. In each code, the return periods of 475 and 975 years were considered. Figure 27 shows the response spectra of each code and return period.

\subsubsection{Application of $\mathrm{N} 2$ method}

The N2 method [59] was used to evaluate the seismic performance of the cathedral. A total of 64 performance points were determined. Those were obtained from 4 directions of 
seismic analysis $\times 4$ control points $\times 2$ codes $\times 2$ return periods. Figure 28 shows, as an example, the application of the method to the evaluation of the seismic performance in $+X$ direction considering the control point CG-cathedral and the Eurocode 8 with a return period of 975 years. The found values were $0,53 \mathrm{~m} / \mathrm{s}^{2}(0,053 \mathrm{~g})$ and $0,004 \mathrm{~m}$ for the performance load multiplier $\left(\mathrm{LM}_{\mathrm{p}}\right)$ and the performance displacement $\left(D_{p}\right)$, respectively.

In Table 7 the obtained results for the performance load multiplier (LMp) and the performance displacement (Dp) are reported. It was always observed that the lowest and the highest Dp and LMp were attributed to the cases of EC-08 with return period of 475 years and NCSE-02 with return period of 975 years, respectively. Near values for Dp and LMp were obtained for the other two cases of EC-08 (return period of 975) and NCSE-02 (return period of 475 years) because the descending branch of these two spectra were near to each other (Figure 27).

To highlight the effect of the control point choice on the evaluation of the cathedral seismic safety, the ratios between the maximum displacements and the $D_{p}$ are shown in Figure 29. In this figure, it is clear that the highest ratios were found (for any of the analysis directions) when using the point Max-D. The two control points CG-cathedral and CG-roof showed near ratios and lesser ones than those of Max-D point. As expected, the point Top presented larger displacements (higher than CG-cathedral and CG-roof and lesser than Max-D) only for the case of $+X$ direction. In the $-X$ direction, the ratios were near to those of CG-cathedral and CG-roof. In the $\pm Y$ directions, the ratios were small. Recalling that the point Top was located on the top of the west façade gable, it seemed that using it for the case of $+X$ direction (the west façade is pushed outside its plane) is appropriate and representative choice. However, using it for the other directions seemed to be inadequate to represent the displacement capacity of the cathedral.

Similarly, the ratios between the collapse load multiplier and the $\mathrm{LM}_{\mathrm{p}}$ are shown in Figure 30. The same comments mentioned on the displacements comparison, can be mentioned again on the load multiplier comparison. It was found that the point Max-D gave the highest ratios and the point Top did not give reasonable values for all directions except the $+X$ one. Slightly higher ratios were obtained for the point CG-roof than those obtained for CG-cathedral. For any combination of demand spectrum, return period, analysis direction and control point, no ratio less than one was found. This is an indicator of the sufficient seismic capacity of the cathedral.

\section{CONCLUSIONS}

A seismic analysis of a large and complex Gothic structure, namely Mallorca cathedral, has been carried out by combining and integrating structural analysis with experimental information. The analysis has involved the updating of the prepared FE model through a modal matching process based on the obtained experimental information on the dynamic response of the building.

The cathedral was subjected to AVT for the characterization of its dynamic parameters. It was possible to identify eight modes. The natural frequencies of all of them were satisfactory identified. However, only the mode shapes and the damping ratios of three modes were 
satisfactory identified. These modes were global ones with high mass participation, which made their identification more attainable than in the case of more local ones.

The identified frequencies and mode shapes were used in a manual approach for updating the FE model of the cathedral. This updating was uncoupled, i.e. the stiffness of the longitudinal direction was adjusted using the first mode shape and then the transversal direction stiffness was adjusted using the second mode shape. The model modification that allowed a higher matching between the experimental and numerical results was the improvement of the model by including secondary structural members not implemented in a first version of the model. For the transversal direction, decreasing the modulus of elasticity of the buttresses improved the modal matching by slightly decreasing the cathedral stiffness in this direction. The numerical model was updated to a satisfactory extend. It reached $\mathrm{D}_{\mathrm{f}}$ values around $2 \%$ or less for two global modes and two local modes affecting mostly single parts of the structure. Moreover, the two global modes of the cathedral had an average MAC of 0,82 .

The updated model was used for the seismic assessment using the nonlinear static (pushover) analysis. The seismic resistance of the cathedral in the longitudinal direction is lower than that in the transversal direction. This is due to the fact that in the former case the buttresses (the main earthquake-resisting elements) are loaded by lateral loads acting in their out-of-plan direction, whereas, in the latter case, the buttresses are loaded in their stronger in-plane direction. In the longitudinal direction, the collapse can occur due to the overturning of the facades. The zones that can be severely damaged are those around the large windows of the clerestory walls and the apse walls, the first bay of the central nave vault after the west faced, and the top and bases of the columns. In the transversal direction, the collapse can occur due to the cracks (hinges) appearing in the flying arches, the arches and vaults of the naves, the top and bases of the columns and the bases of the buttresses.

A sensitivity analysis was carried by changing the used properties of materials in the FE model. Changing the tensile strength was found to be very influential on the capacity. Both the capacity and the maximum displacement were observed to change significantly with the variation of the modulus of elasticity. The capacity and the maximum displacement varied only slightly when increasing the compressive strength or the ultimate crack strain, but they were reduced significantly when reducing these two material parameters.

The N2 method was used to evaluate the seismic performance. The cathedral showed an acceptable seismic performance evaluated in terms of the ratios between the maximum displacements and capacities and their performance counterparts. Therefore, deep interventions involving a significant transformation of the structure were deemed inadequate. However, deep repair of cracks would be advisable to reintegrate, as much as possible, the initial energy dissipation capacity of the structure.

\section{Acknowledgment}

This research has been carried out within the project "New Integrated Knowledge based approaches to the protection of cultural heritage from Earthquake-induced Risk-NIKER" funded by the European Commission (Grant Agreement $\mathrm{n}^{\circ}$ 244123), whose assistance is gratefully acknowledged. 


\section{References}

1) J. G. Ruiz-Pinilla, J. M. Adam, R. Pérez-Cárcel, J. Yuste, J. J. Moragues, Learning from RC building structures damaged by the earthquake in Lorca, Spain, in 2011. Eng. Fail. Anal. 68 (2016) 76-86, http://dx.doi.org/10.1016/j.engfailanal.2016.05.013.

2) J. V. Lemos, C. S. Oliveira, M. Navarro, 3-D nonlinear behavior of an obelisk subjected to the Lorca May 11, 2011 strong motion record. Eng. Fail. Anal. 58 (2015), 212-228, http://dx.doi.org/10.1016/j.engfailanal.2015.09.001.

3) L. Basset-Salom, A. Guardiola-Víllora, Seismic performance of masonry residential buildings in Lorca's city centre, after the 11th May 2011 earthquake. Bull. Earthquake Eng. 12 (2014), 20272048, doi:10.1007/s10518-013-9559-8.

4) A. Benavent-Climent, A. Escobedo, J. Donaire-Avila, E. Oliver-Saiz, A. L. Ramírez-Márquez, Assessment of expected damage on buildings subjected to Lorca earthquake through an energybased seismic index method and nonlinear dynamic response analyses. Bull. Earthquake Eng. 12(2014), 2049-2073, doi:10.1007/s10518-013-9513-9.

5) F. De Luca, G. M. Verderame, F. Gómez-Martínez, A. Pérez-García, The structural role played by masonry infills on RC building performances after the 2011 Lorca, Spain, earthquake. Bull. Earthquake Eng. 12(2014), 1999-2026, doi:10.1007/s10518-013-9500-1.

6) A. Rivas-Medina, S. Martínez-Cuevas, L. E. Quirós, J. M. Gaspar-Escribano, A. Staller, Models for reproducing the damage scenario of the Lorca earthquake, Bull. Earthquake Eng. 12(2014), 2075-2093, doi:10.1007/s10518-014-9593-1

7) X. Romao, A. A. Costa, E. Paupério, H. Rodrigues, R. Vicente, H. Varum, A. Costa, Field observations and interpretation of the structural performance of constructions after the 11 May 2011 Lorca earthquake, Eng. Fail. Anal. 34(2013), 670-692, http://dx.doi.org/10.1016/j.engfailanal.2013.01.040

8) M. Feriche, F. Vidal, G. Alguacill, C. Arandal, J. Pérez-Muelas, M. Navarro, A. Lemme, Performance of culutral heritage of Lorca (Spain) during the two small earthquakes of May 11th, 2011. In Proc. of the 15th World Conference on Earthquake Engineering, 24-28 September, Lisbon. Portugal (2012).

9) G. Brandonisio, G. Lucibello, E. Mele, A. D. Luca. Damage and performance evaluation of masonry churches in the 2009 L'Aquila earthquake. Eng. Fail. Anal. 34(2013), 693-714.

10) S. Lagomarsino, Damage assessment of churches after L'Aquila earthquake (2009). Bull. Earthquake Eng. 10(2012), 73-92.

11) S. Cattari, S. Degli Abbati, D. Ferretti, S. Lagomarsino, D. Ottonelli, A. Tralli, Damage assessment of fortresses after the 2012 Emilia earthquake (Italy), Bull. Earthquake Eng. 12(2014) 2333-2365.

12) L. Sorrentino, L. Liberatore, L. D. Decanini, D. Liberatore, The performance of churches in the 2012 Emilia earthquakes. Bull. Earthquake Eng. 12 (2013) 2299-2331.

13) V. Akansel, G. Ameri, A. Askan, A. Caner, B. Erdil, Ö. Kale, D. Okuyucu, The 23 October 2011 Mw 7.0 Van (Eastern Turkey) earthquake: Interpretations of recorded strong ground motions and post-earthquake conditions of nearby structures. Earthquake Spectra 30(2013).

14) M. Tapan, M. Comert, C. Demir, Y. Sayan, K. Orakcal, A. Ilki, Failures of structures during the October 23, 2011 Tabanlı (Van) and November 9, 2011 Edremit (Van) earthquakes in Turkey. Eng. Fail. Anal. 34(2013), 606-628.

15) PERPETUATE, Performance-based approach to the earthquake protection of cultural heritage in European and Mediterranean countries. Funded by EC under the 7th Framework program, grant agreement $\mathrm{n}^{\circ}$ 244229. www. perpetuate.eu, (2010-2012).

16) SEVERES, Seismic vulnerability of old masony buildings. Funded by Portuguese Foundation for Science and Technology, contract n. PTDC/ECM/100872/2008, www.severes.org, (2010-2012). 
17) PROHITECH, Earthquake PROtection of HIstorical Buildings by Reversible Mixed TECHnologies, Funded by EC under the 6th Framework program grant No. INCO-CT-2004509119, (2004-2008).

18) EU-India, Improving the seismic resistance of cultural heritage buildings. Funded by EU-INDIA Economic Cross Cultural Programme, contract n. ALA/95/23/2003/077-122, (2004-2006).

19) RISK-UE. An advanced approach to earthquake risk scenarios with applications to different European towns. Funded by EC, contract n. EVK4-CT-2000-00014m (2001-2004).

20) CHIME, Conservation of historical Mediterranean sites by innovative seismic protection techniques. Funded by EC under the 5th Framework program, (2000-2003).

21) NIKER, New Integrated Knowledge-based approaches to the protection of cultural heritage from Earthquake-induced Risk. Funded by EC under the 7th Framework program, contract $n$. ENV2009-1-GA244123. (2010-2012), www.niker.eu.

22) ISO 13822 (2010). Assessment of existing structures. International Organization for Standardization.

23) A. Elyamani Integrated monitoring and structural analysis strategies for the study of large historical construction. Application to Mallorca cathedral, $\mathrm{PhD}$ thesis, Technical University of Catalonia, Spain, (2015).

24) O. Caselles, G. Martínez, J. Clapes, P. Roca, M. D. L. V. Pérez-Gracia, Application of particle motion technique to structural modal identification of heritage buildings. International Journal of Architectural Heritage 9(2015) 310-323.

25) L. Pelà, J. Bourgeois, P. Roca, M. Cervera, M. Chiumenti, Analysis of the Effect of Provisional Ties on the Construction and Current Deformation of Mallorca Cathedral. International Journal of Architectural Heritage (2014). DOI: 10.1080/15583058.2014.996920

26) P. Roca, M. Cervera, L. Pelà, R. Clemente, M. Chiumenti, Continuum FE models for the analysis of Mallorca Cathedral. Engineering Structures 46 (2013) 653-670

27) P. Roca, M. Cervera, L. Pelà, R. Clemente, M. Chiumenti, Viscoelasticity and Damage Model for Creep Behavior of Historical Masonry Structures, The Open Civil Engineering Journal (2012) 6.

28) A. Elyamani, O. Caselles, J. Clapes, P. Roca, Assessment of dynamic behavior of Mallorca Cathedral. In Structural Analysis of Historical Constructions. Proceedings of the International Conference on Structural Analysis of Historical Constructions, SAHC (2012), 2376-2384.

29) R. González, F. Caballé, J. Domenge, M. Vendrell, P. Giráldez, P. Roca, J. L. González, Construction process, damage and structural analysis. Two case studies. In D'Ayala, D. and Fodde, E. (Eds.) Structural Analysis of Historical Construction. CRC Press Balkema, (2008), 643-651.

30) P. Roca, Studies on the structure of Gothic cathedrals. In: Lourenço, P.B. and Roca, P. (Eds.) Historical Constructions, University of Minho, Guimarães, (2001), 71-90.

31) V. Pérez-Gracia, J. O. Caselles, J. Clapés, G. Martinez, R. Osorio, Non-destructive analysis in cultural heritage buildings: Evaluating the Mallorca cathedral supporting structures. NDT \& E International, 59 (2013), 40-47.

32) IGN, Catálogo Sísmico de España. Servicio de Sismología, Instituto Geográfico Nacional, Petición de datos $n^{\circ}$ 96/0001 by Silva, P. G., Hernández, F. G., Goy, J. L., Zazo, C., \& Carrasco, P. (2001). Paleo and historical seismicity in Mallorca (Baleares, Spain): a preliminary approach. Acta geológica hispánica, 36 (1996), 245-266.

33) P. G. Silva, F. G. Hernández, J. L. Goy, C. Zazo, P. Carrasco, Paleo and historical seismicity in Mallorca (Baleares, Spain): a preliminary approach. Acta geológica hispánica, 36 (2001), 245266.

34) J. Giménez, B. Gelabert, Recent Tectonic ActiVity Analysis of Mallorca Island. In EGS General Assembly Conference Abstracts 27 (2002), p. 4526.

35) J. Mezcua, J. M. Martínez Solares, Sismicidad del área Ibero-mogrebí. Presidencia del Gobierno, IGN, Publicación 203 (1983), 299 pp. 
36) E. Fontseré, J. Iglésies, Recopilació de dades sísmiques de les terres Catalanes entre 1100 i 1906. Ed. Fundació Salvador Vives Casajoana, (1971).

37) P. Bouby, Sobre el terremoto ocurrido en la isla de Mallorca el 15 de Mayo último". Revista Minera, II (26) (1851), 356-375.

38) J. Galbis, Catálogo Sísmico de la zona comprendida entre los meridianos $5^{\circ} \mathrm{E}$ y $20^{\circ} \mathrm{W}$ de Greenwich y los paralelos $45^{\circ}$ y $25^{\circ} \mathrm{N}$. Inst. Geogr á fico, Catastral y de Estadística de España, Tomo I, (1932), 99-100.

39) M. Pujó, Le tremblement de terre du 15 mai 1851 de l'île de Majorque. Comp. Rend. Acad. Sci. Paris, 2 (1851).

40) A. Elyamani, J. O. Caselles, P. Roca, and J. Clape, J Dynamic investigation of a large historical cathedral. Structural Control and Health Monitoirng (2016). DOI: 10.1002/stc.1885.

41) MACEC 3.2 a MATLAB Toolbox for Experimental and Operational Modal Analysis, Developed by Reynders E, De Roeck G, Copyright (C) KU Leuven, Belgium, 2011.

42) R. Brincker, L. Zhang, P. Andersen Modal identification of output-only systems using frequency domain decomposition. Smart materials and structures 10 (2001), 441- 445.

43) B. Peeters, G. De Roeck, Reference-based stochastic subspace identification for output-only modal analysis. Mechanical Systems and Signal Processing 13 (1999), 855-878.

44) B. Peeters, H. Van der Auweraer, PolyMAX: a revolution in operational modal analysis. 1st International Operational Modal Analysis Conference (IOMAC), (2005), 26-27 April, Copenhagen, Denmark.

45) GiD (2002). GID: the personal pre and post-processor. Barcelona: CIMNE, Technical University of Catalonia; 2002. <http://gid.cimne.upc.es>.

46) DIANA, Diana 9.4, user's manual. The Netherlands: TNO Building and Construction Research. Available from www.diana.tno.nl, (2009).

47) J. R. Allemang, The modal assurance criterion - twenty years of use \& abuse. Sound and Vibration 37 (2003), 14-21.

48) C. Gentile, A. Saisi, Ambient vibration testing of historic masonry towers for structural identification and damage assessment. Const. Build. Mat., 21 (2007), 1311-1321.

49) V. Pérez-Gracia, J. O. Caselles, J. Clapes, R. Osorio, G. Martínez, J. A. Canas, Integrated nearsurface geophysical survey of the Cathedral of Mallorca. J. Arch. Sci., 36 (2009), 1289-1299.

50) G. Martínez, Seismic vulnerability for middle and long span masonry historical buildings (in Spanish). PhD thesis, Technical University of Catalonia, Barcelona,Spain, (2007).

51) J. L. González, P. Roca, Study of Structural-Constructive Behavior of Saint Mary Cathedral in the City Of Palma, Mallorca Island (Baleares). First Phase: Part I. (2003), Part II (2003), Part III (2004), Part IV (2004). Second Phase: Part V. (2008), Part VI (2008), Technical University of Catalonia, Spain, (In Spanish), (2003-2008).

52) L. Pelà, A. Aprile, A. Benedetti, Seismic assessment of masonry arch bridges, Eng. Str. 31 (2009), 1777-1788.

53) S. Saloustros, L. Pelà, P. Roca, J. Portal, Numerical analysis of structural damage in the church of the Poblet monastery. Eng. Fail. Anal. 48(2015),41-61, http://dx.doi.org/10.1016/j.engfailanal.2014.10.015 .

54) N. Ademovic, M. Hrasnica, D. V. Oliveira, Pushover analysis and failure pattern of a typical masonry residential building in Bosnia and Herzegovina. Eng. Str. 50 (2013), 13-29.

55) A. Elyamani, Conservation-Oriented Structural Analysis of the Spire of Barcelona Cathedral. Int. J. Mat. Sci. App. (2016)5, 1-9. doi: 10.11648/j.ijmsa.s.2016050602.11.

56) A. Elyamani, Wind and earthquake analysis of spire of cimborio of Barcelona cathedral, MSc Thesis, Technical University of Catalonia, (2009).

57) NCSE-02 (2002). Norma de construcción sismo resistente - Parte general y edificación. (In Spanish). 
58) CEN (2004) Eurocode 8 - Design Provisions for Earthquake Resistance of Structures, Part 1.1: General rules, seismic actions and rules for buildings, European prestandards ENV 1998, European Committee for Standardization, Brussels.

59) P. A. Fajfar, A nonlinear analysis method for performance-based seismic design. Earthquake Spectra 16 (2000), 573-592. 


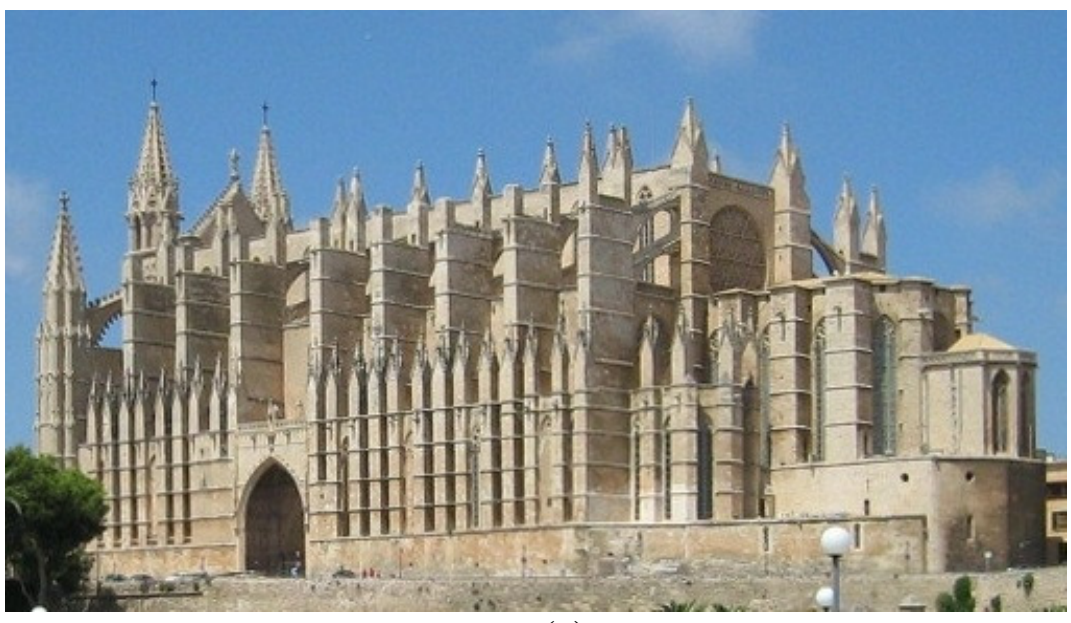

(a)

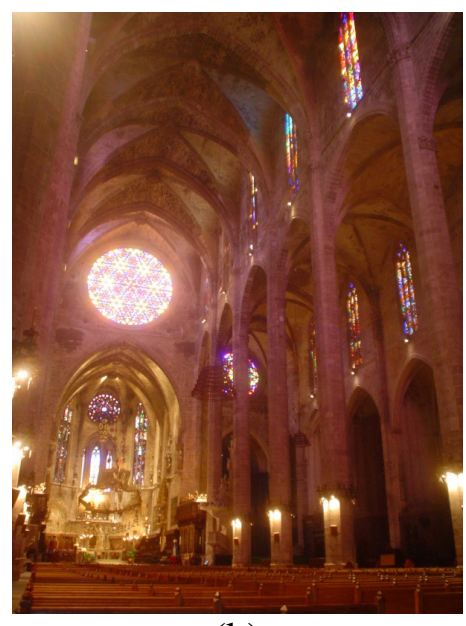

(b)

Figure 1. Mallorca Cathedral: (a) from outside, and (b) from inside. 


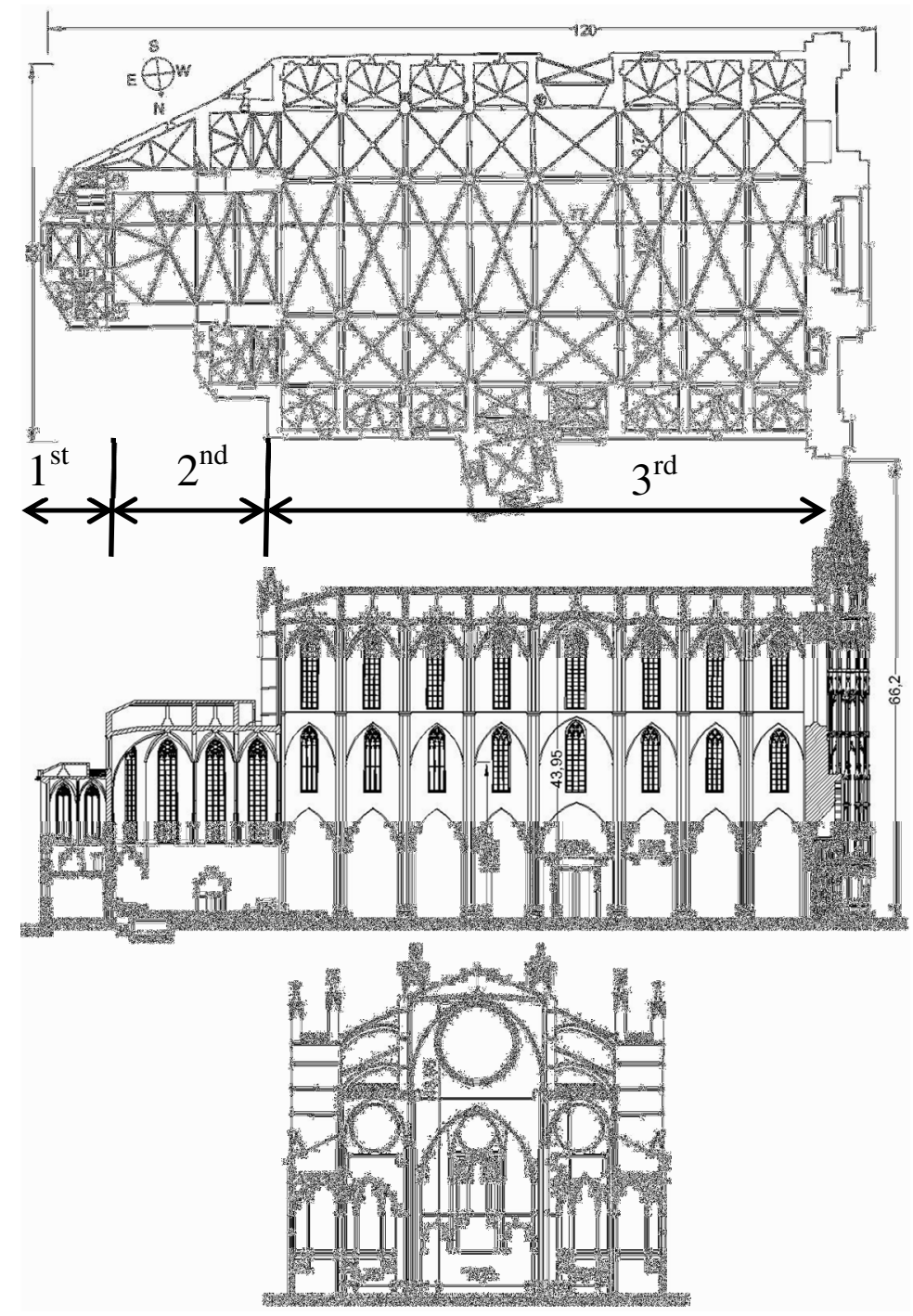

Figure 2.Mallorca cathedral: plan (top); longitudinal section (center); and transversal section (bottom) (from Director Plan of Mallorca Cathedral). 


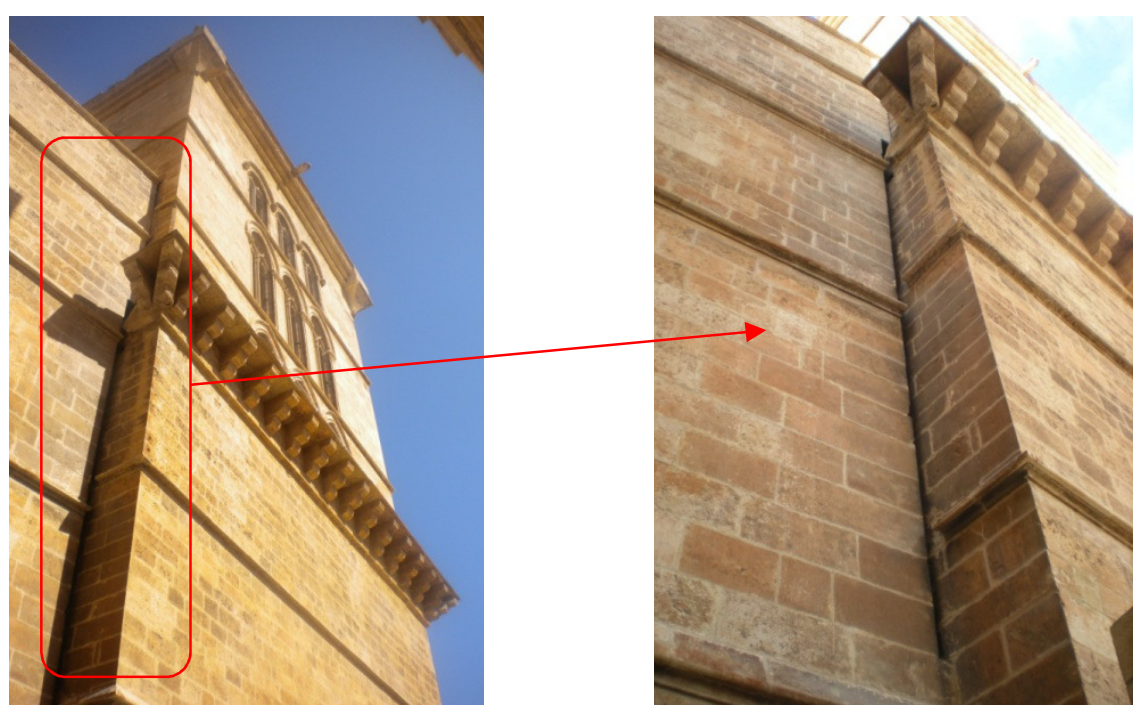

Figure 3. View to the tower-buttress relation (left); and zoom to the separation (right). 

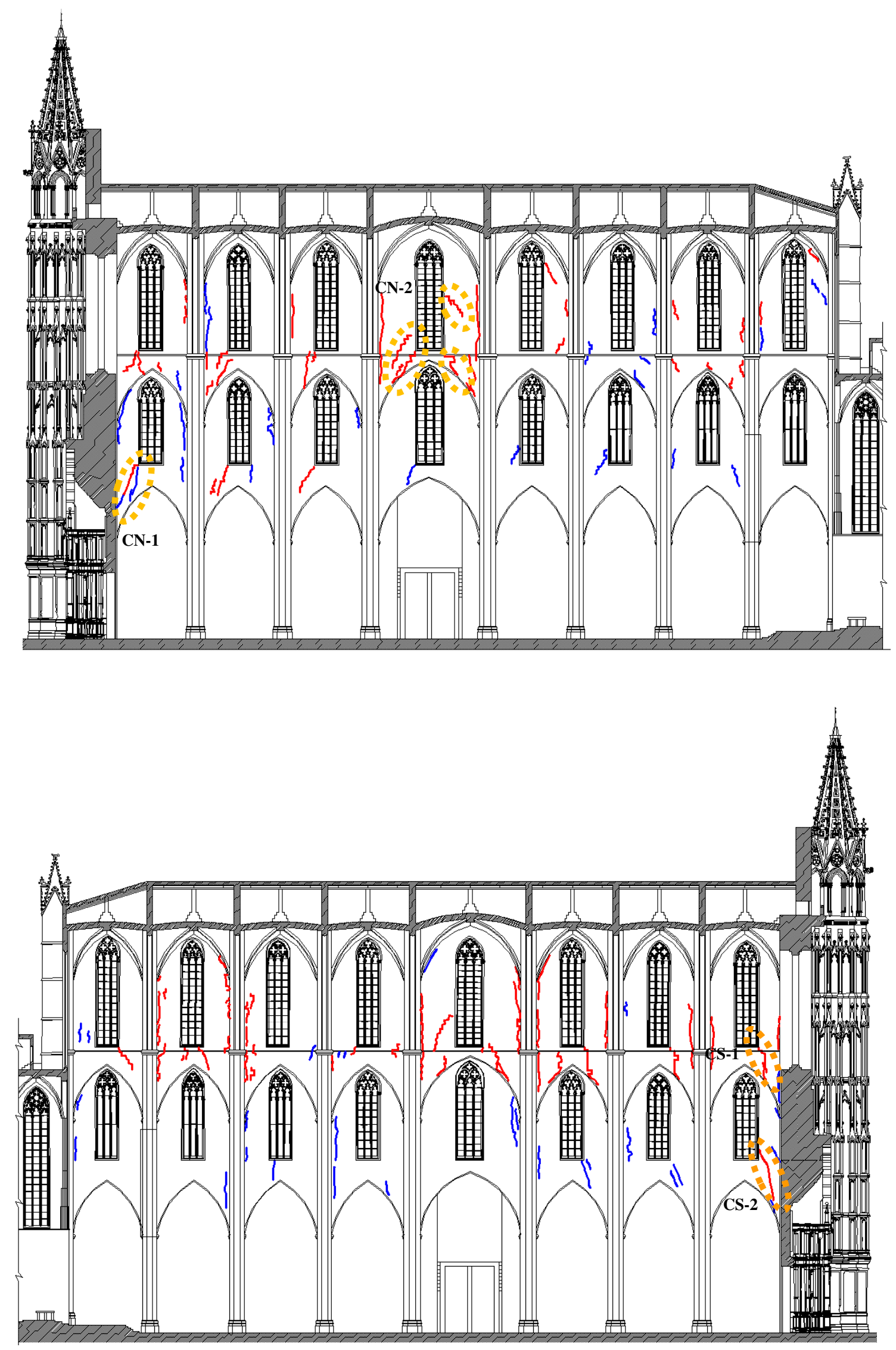
Figure 4. Crack survey of north (top) and south (bottom) clerestory walls before a recent repair. Red cracks are wider than blue ones. Pictures of cracks surrounded by ellipses are shown in the next figure. 


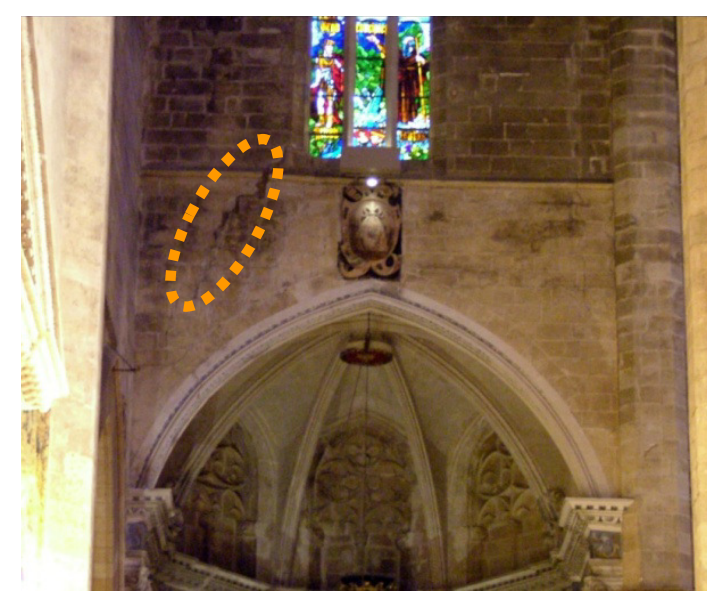

$\mathrm{CN}-1$

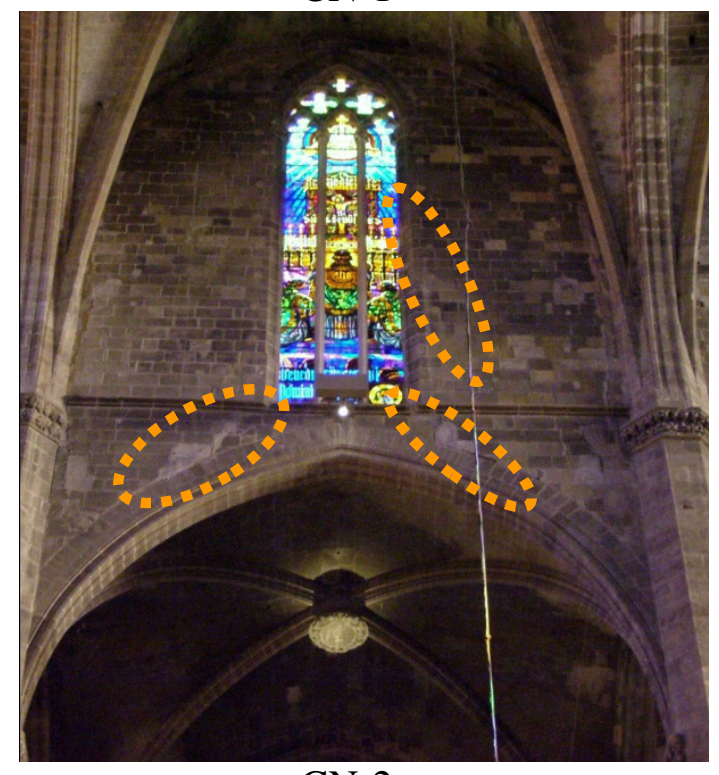

$\mathrm{CN}-2$

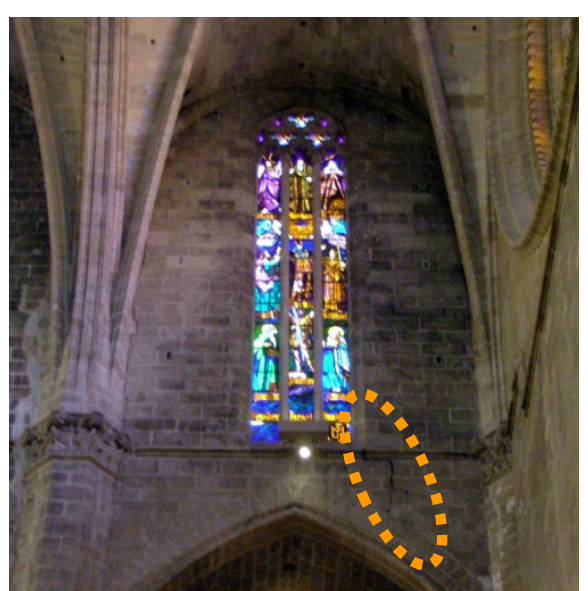

CS-1

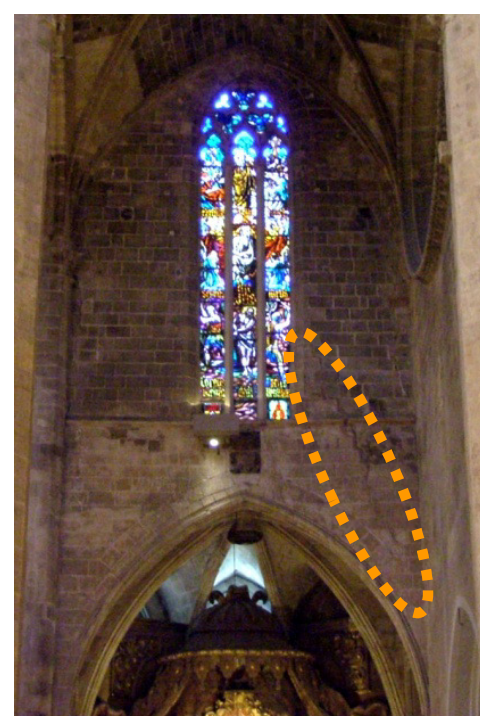

CS-2

Figure 5. Pictures of some of the cracks indicated of the previous figure seen from the interior of the cathedral. 


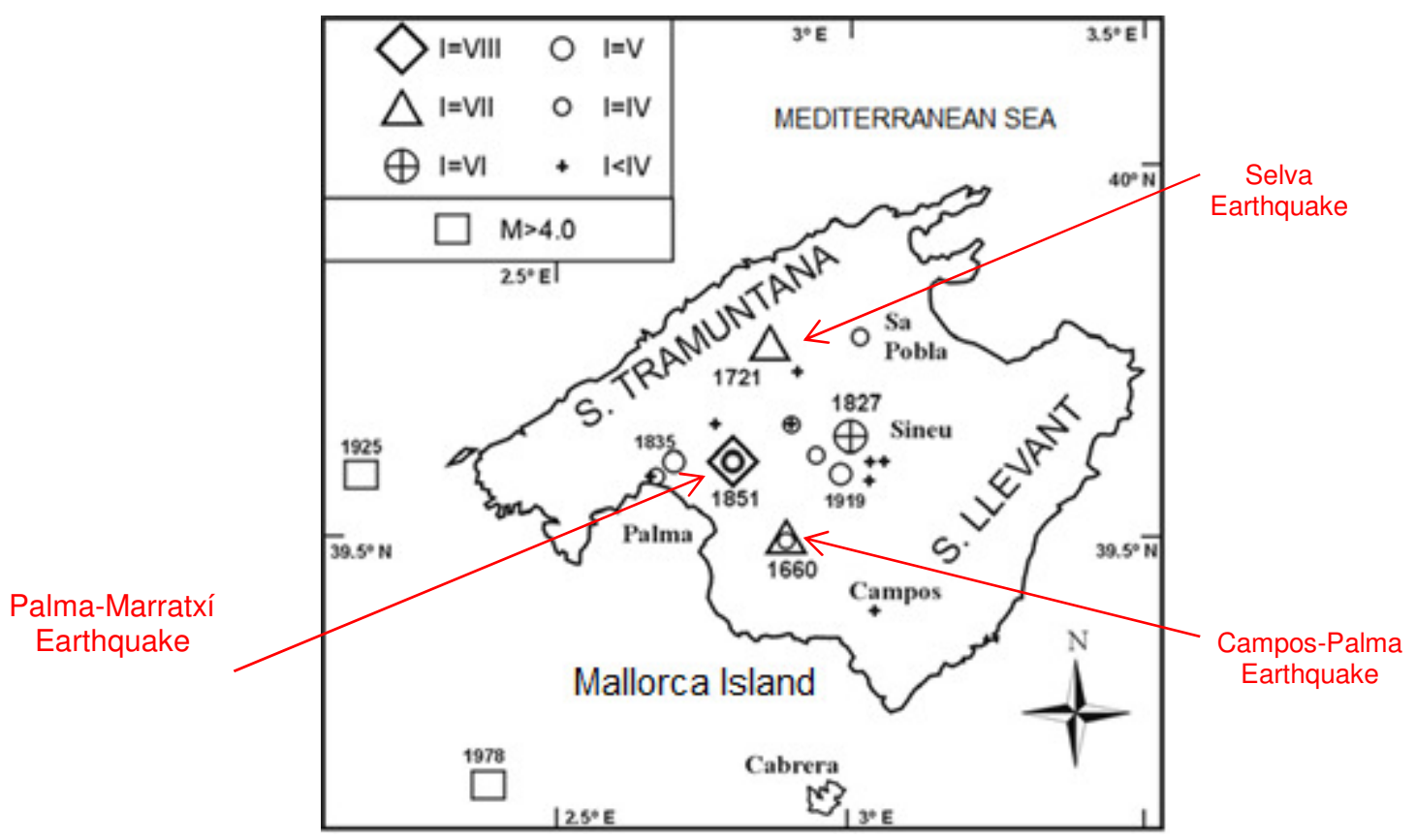

Figure 6. Epicenter of earthquakes having hit Mallorca Island with MSK scale intensities from IV to VIII and with M scale above 4.0 (Source: [34] adopted from [35]) 
a)

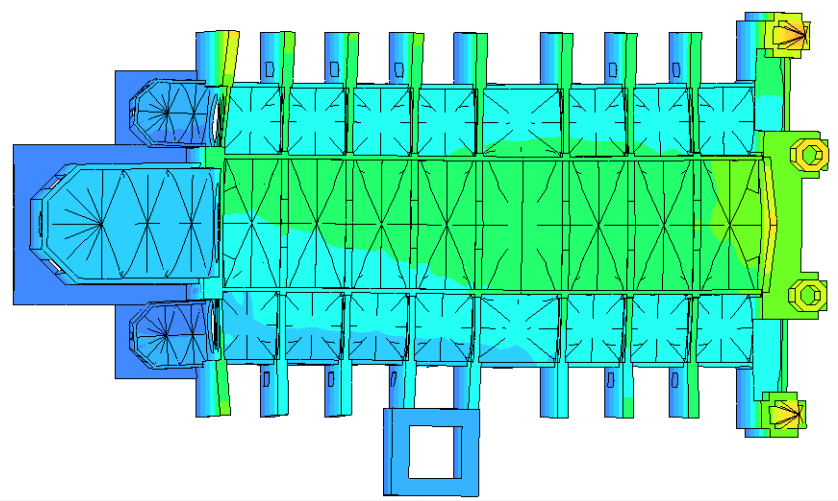

b)

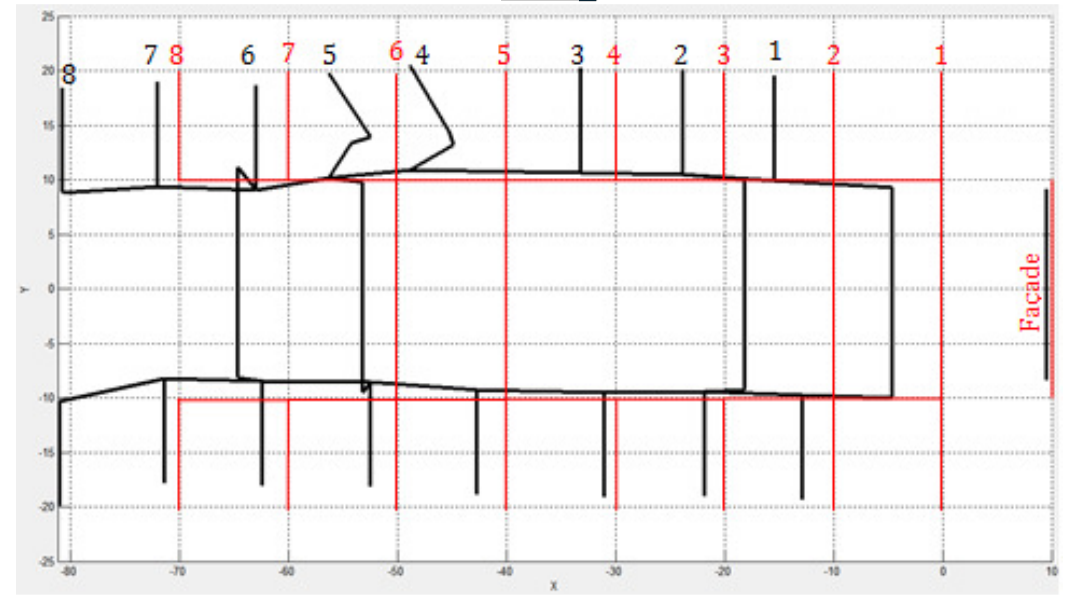

Figure 7. (a) First numerical mode shape, and (b) second experimental mode shape.

c)

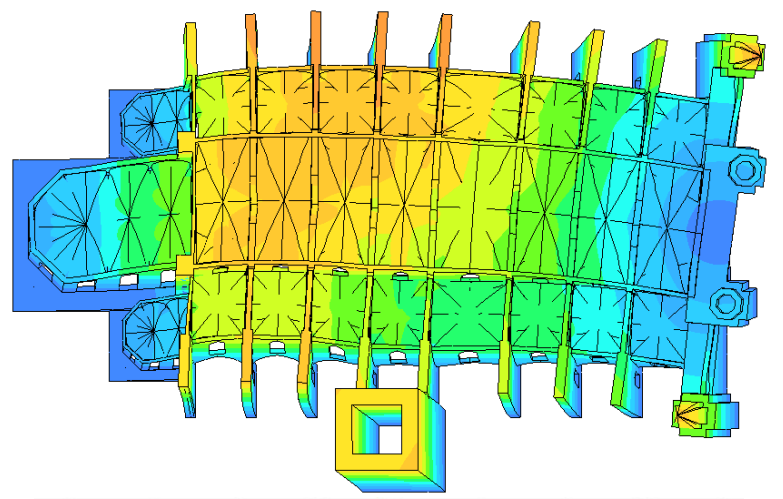

d)

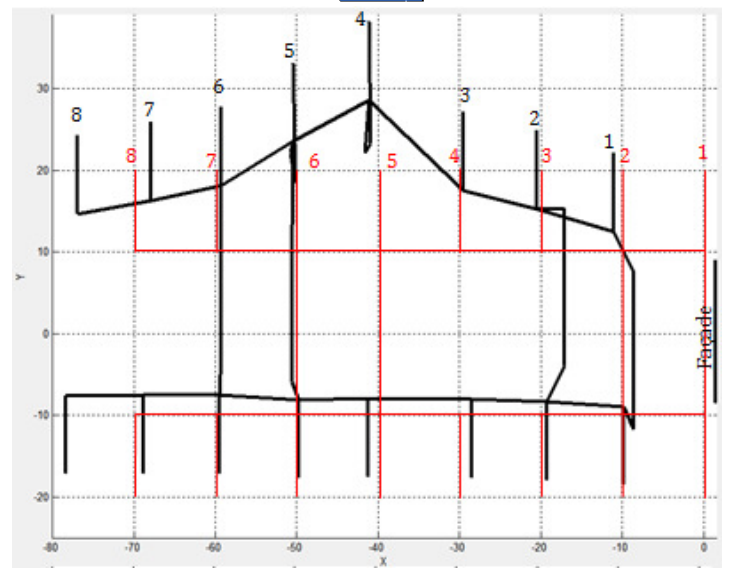

Figure 8. (a) Second numerical mode shape, and (b) fourth experimental mode shape. 


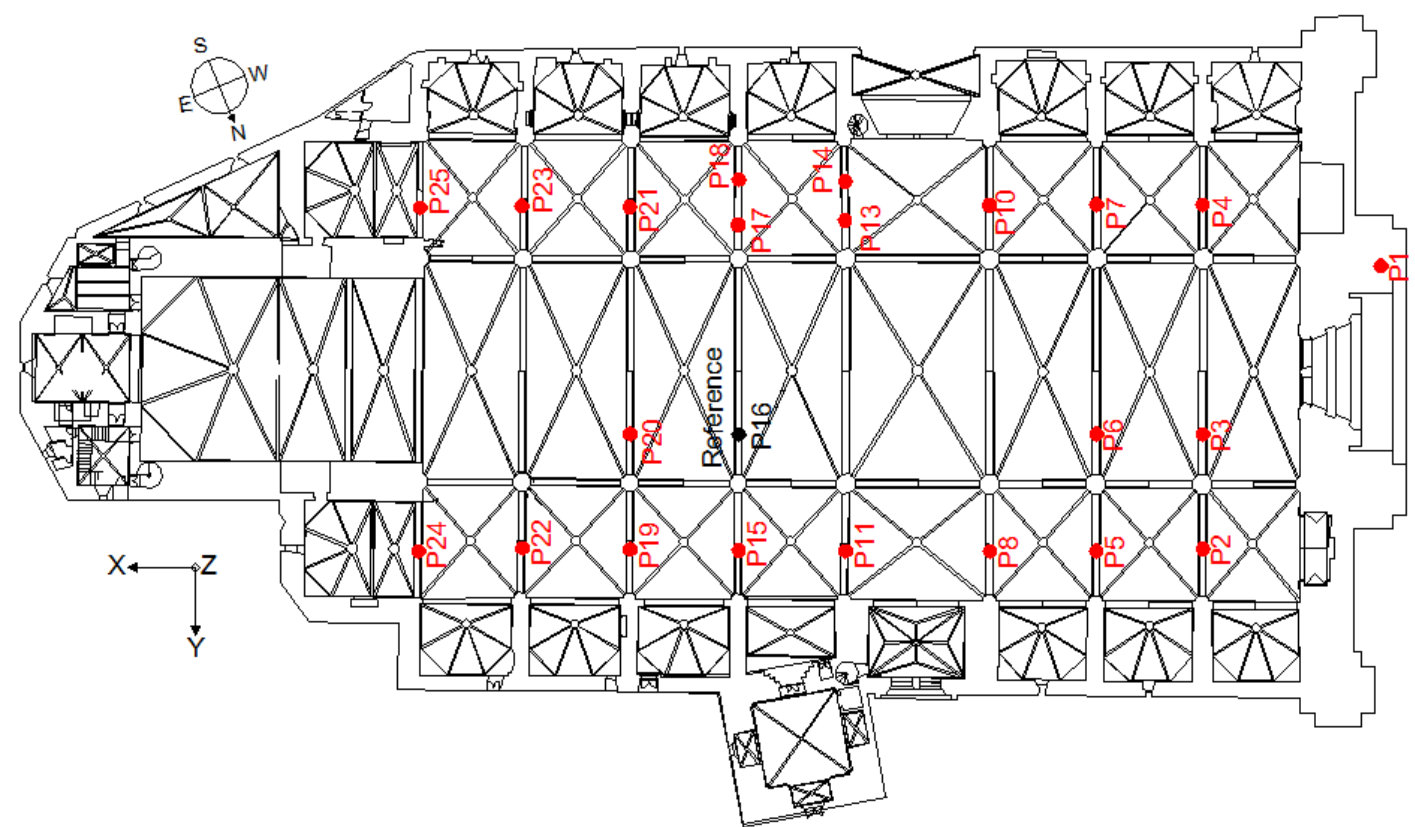

Figure 9. Locations of sensors during AVT. All the points were located on the roof of the cathedral. 

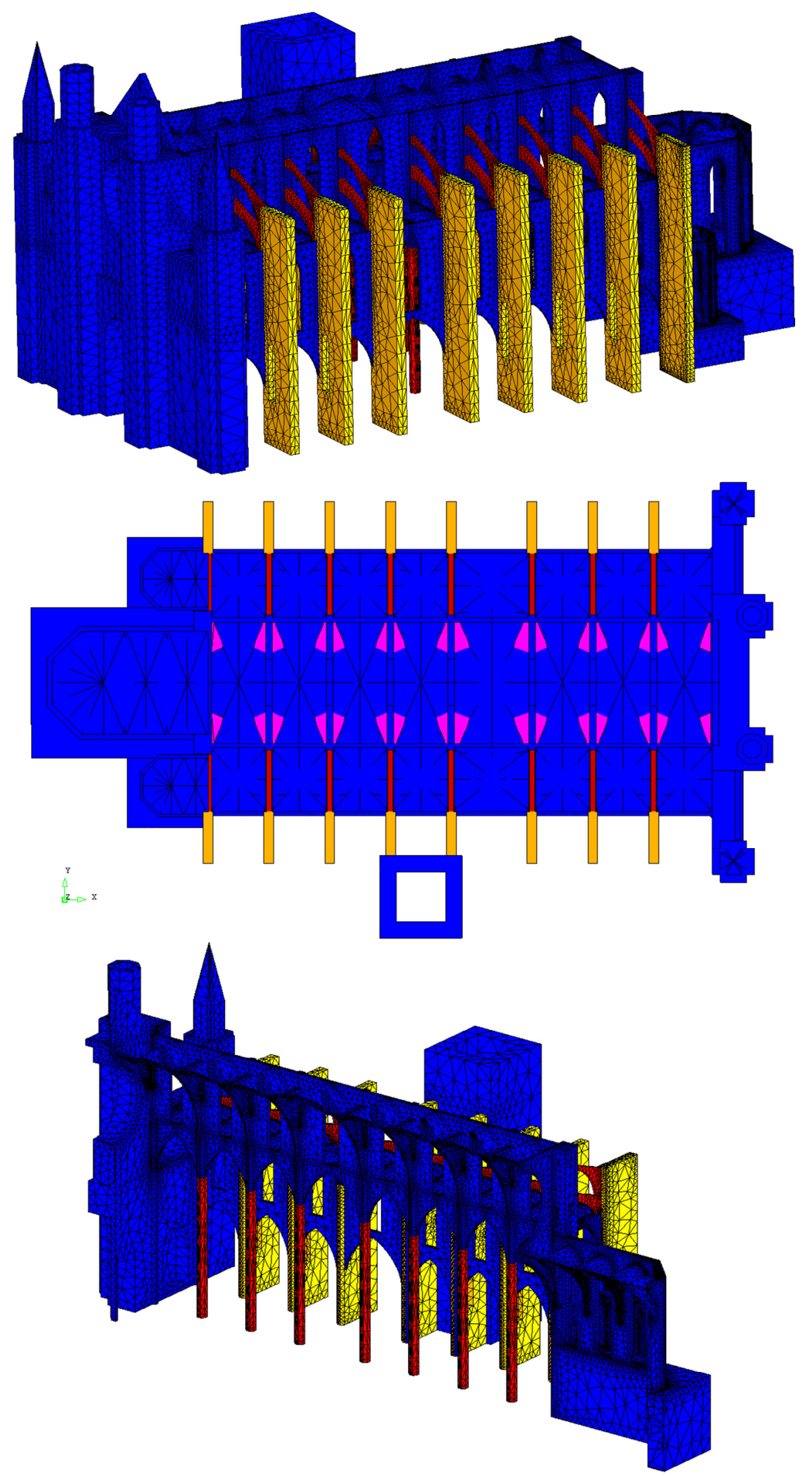

Figure 10. Views of the FE model: complete model (top); plan showing filling above vaults in 
magenta (center); and longitudinal section (bottom). 

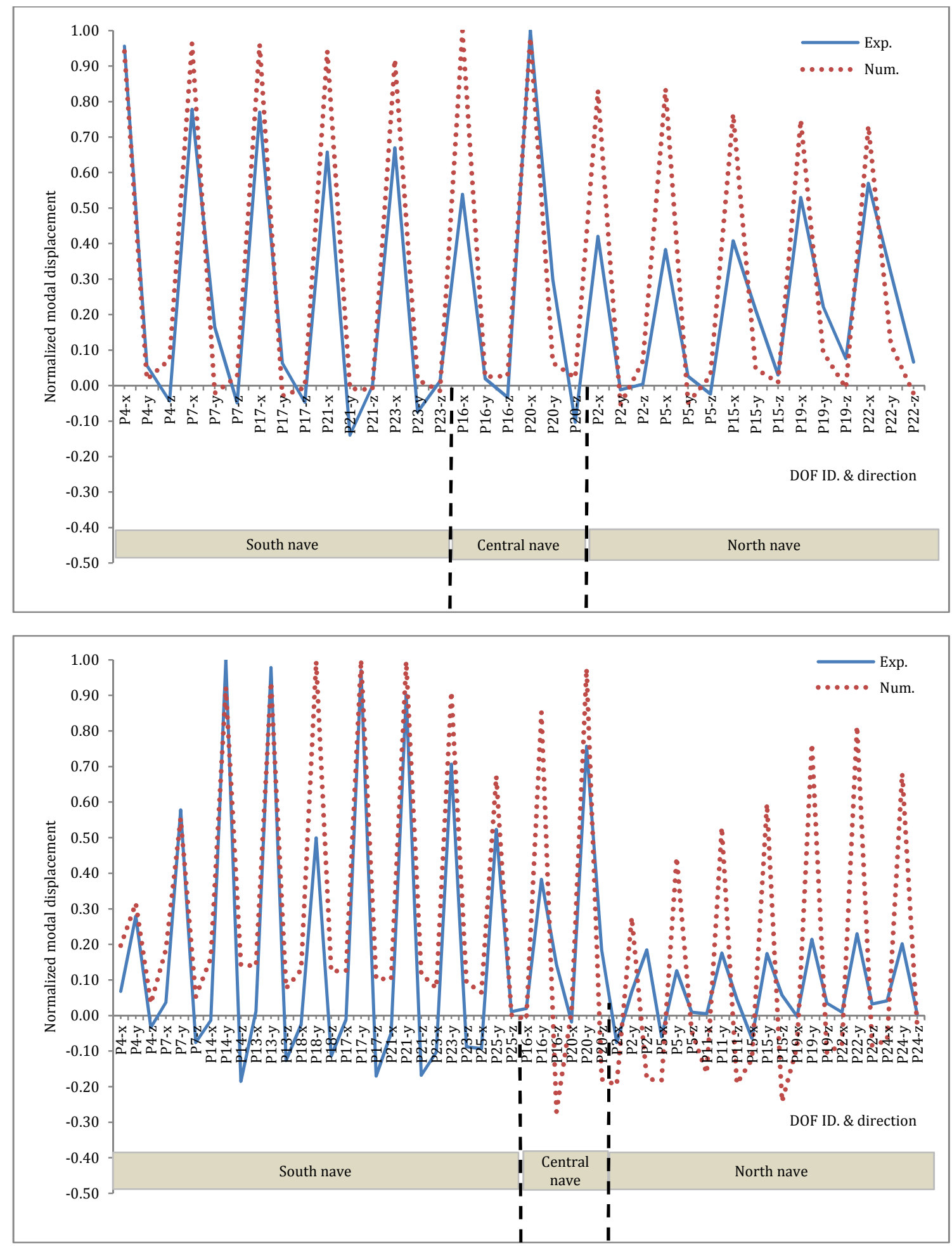

Figure 11. Comparison between mode shapes of 1Num-2Exp (top); and 2Num-4Exp (bottom). The points on the horizontal axes refer to measurement points during AVT. 


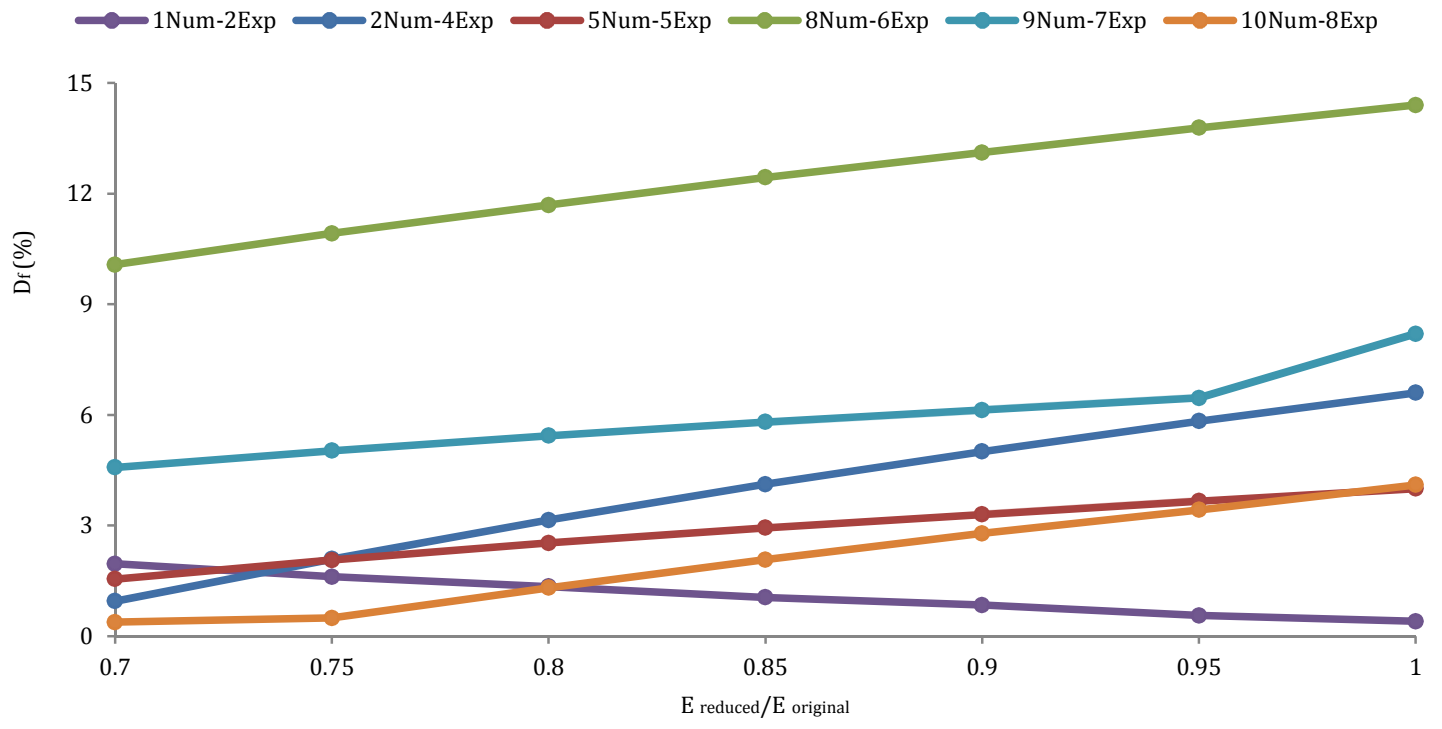

Figure 12. Variation of the $\mathrm{D}_{\mathrm{f}}$ of different vibration modes with the elasticity modulus of the buttresses. 


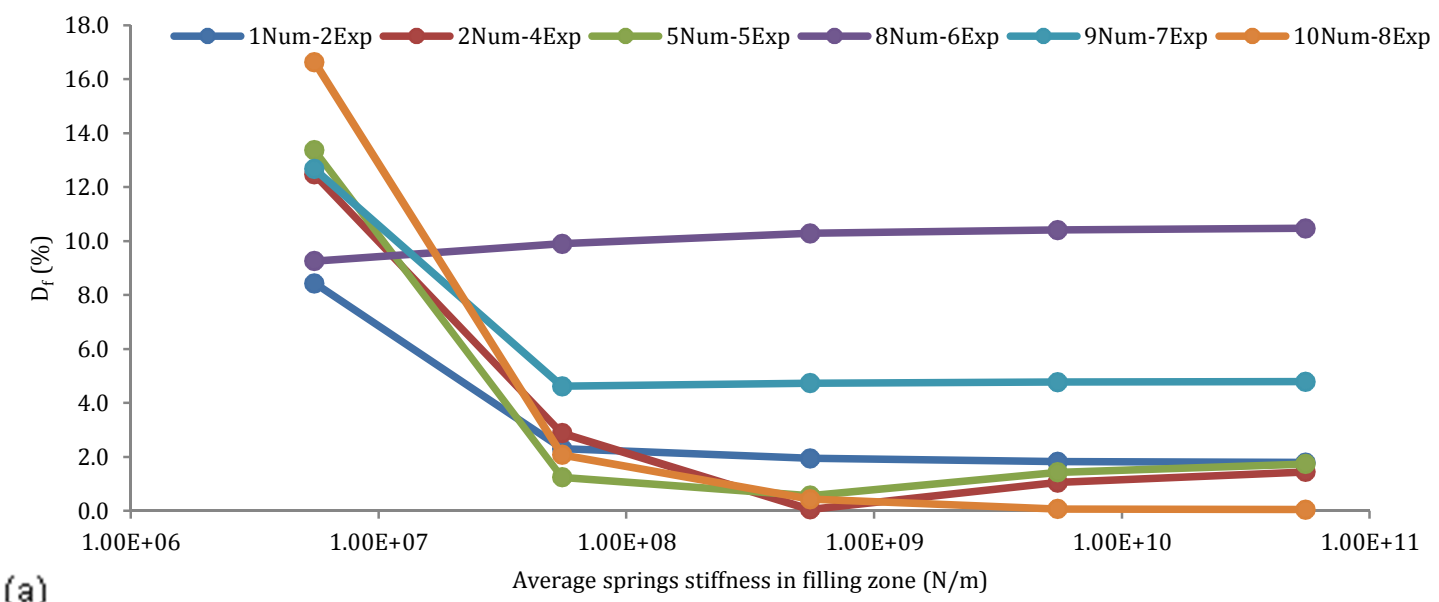

(a)

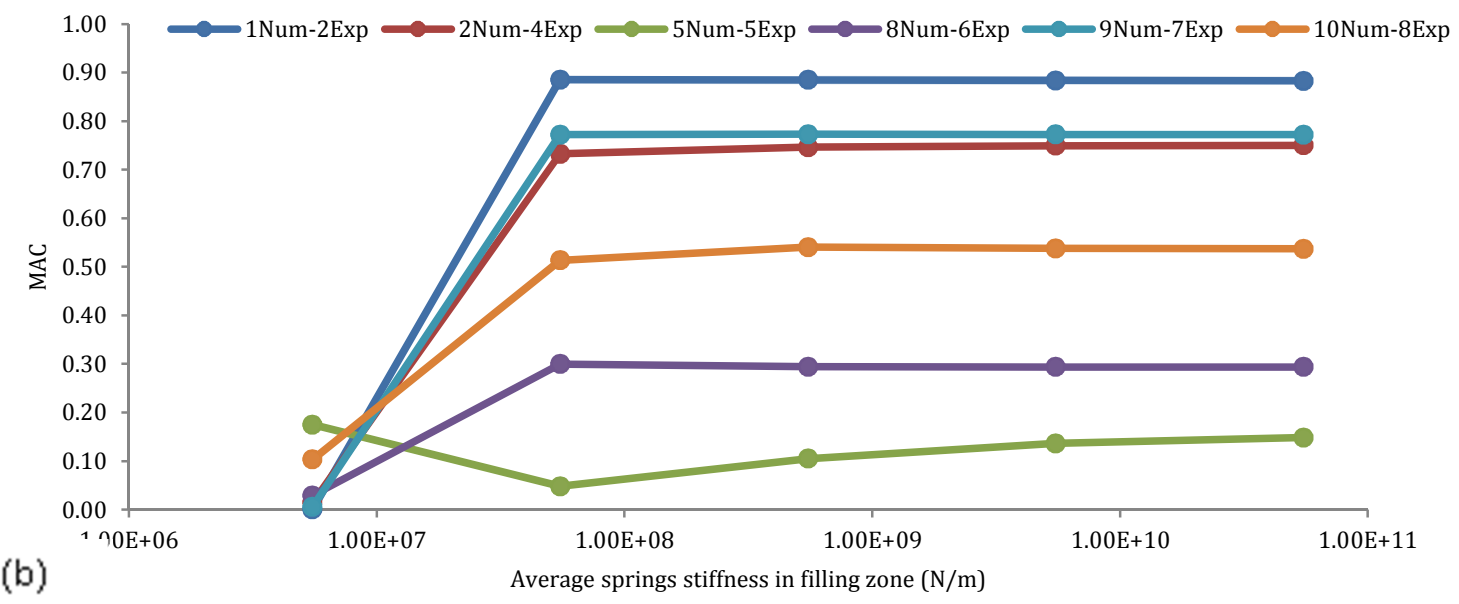

Figure 13. Effect of changing the average spring stiffness in the filling zone on: (a) $\mathrm{D}_{\mathrm{f}}$; and (b) MAC. 

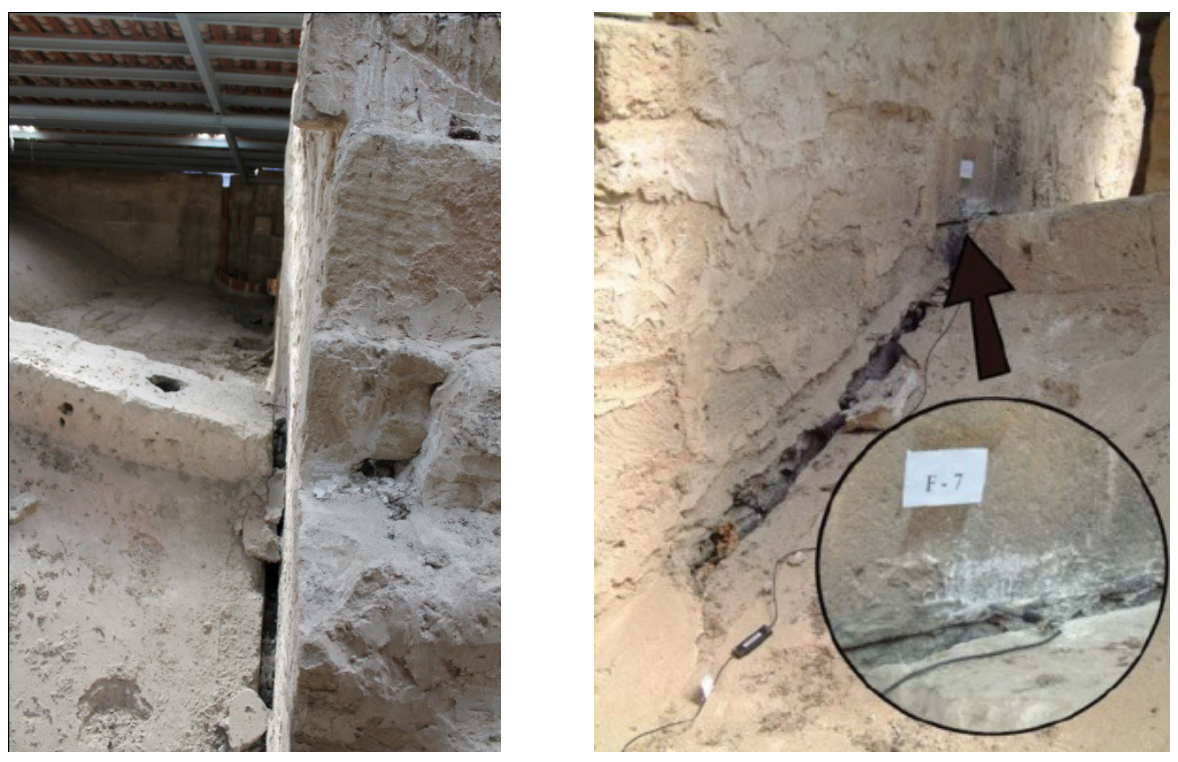

Figure 14. The crack between the third arch and the fourth vault (left) and a zoom to the static monitoring sensor (right). 


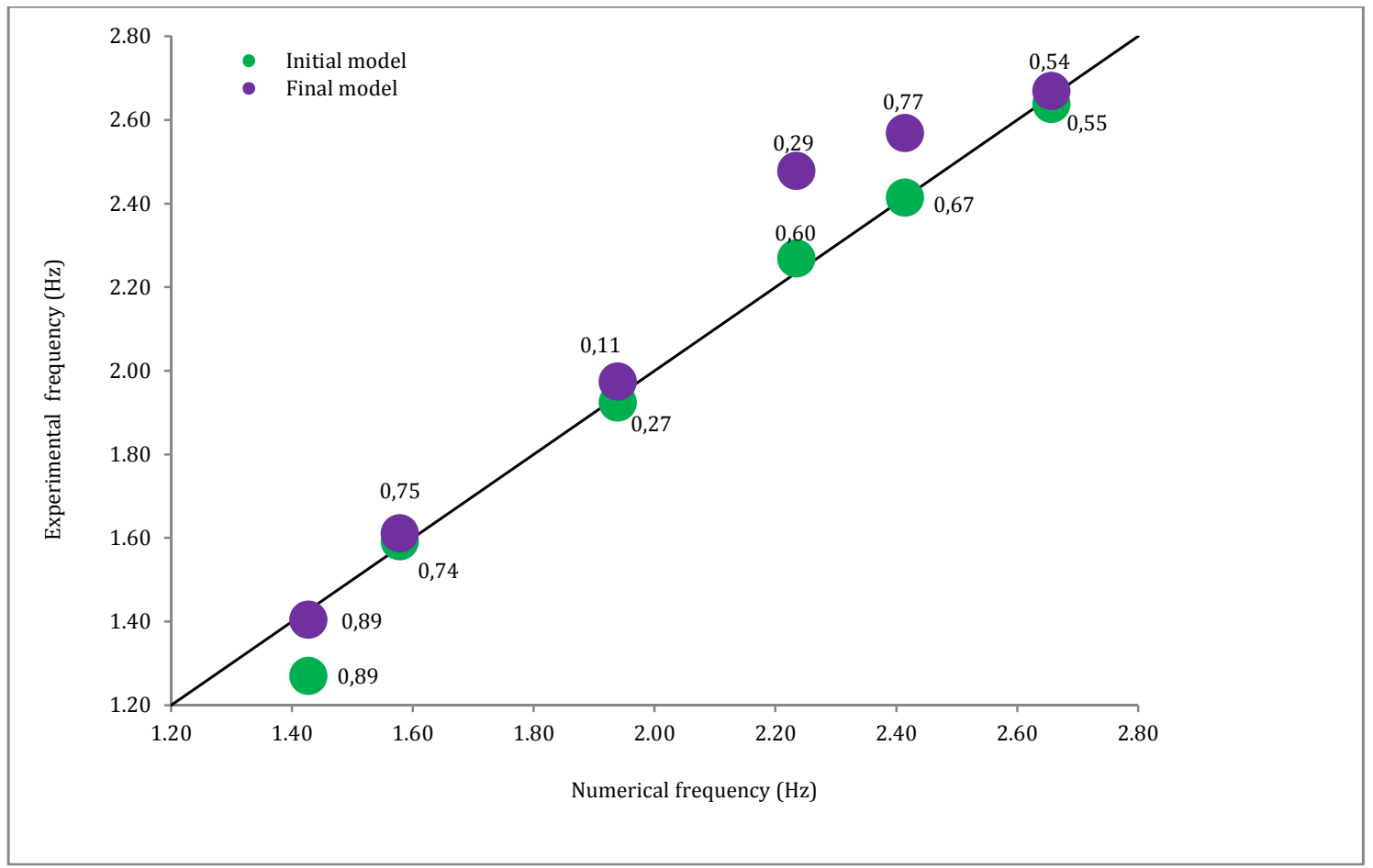

Figure 15. Comparison between the experimental frequencies and the frequencies of the initial and the final models, the MAC values are shown beside the dots. 


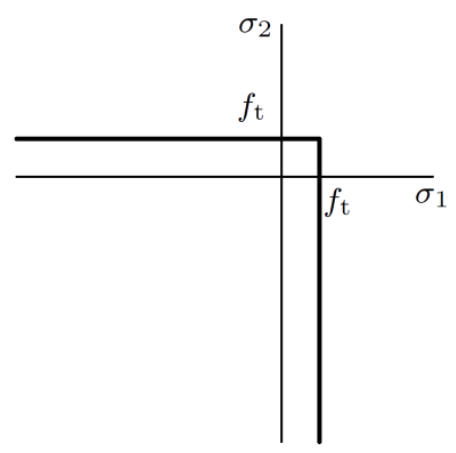

(a)

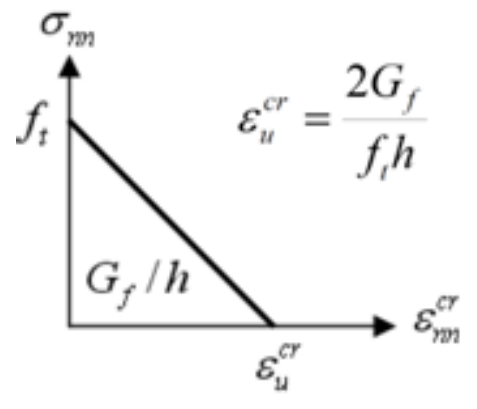

(b)

Figure 16. Representation of (a) tension cut-off and (b) tension softening (DIANA, 2009). $\sigma_{1}$ and $\sigma_{2}$ are the two-dimensional principal stresses. $\mathrm{G}_{\mathrm{f}}$ is the fracture energy in tension, $\varepsilon_{u}^{c r}$ is the ultimate crack strain, $\mathrm{h}$ is the crack band width taken as the cubic root of the element volume. 


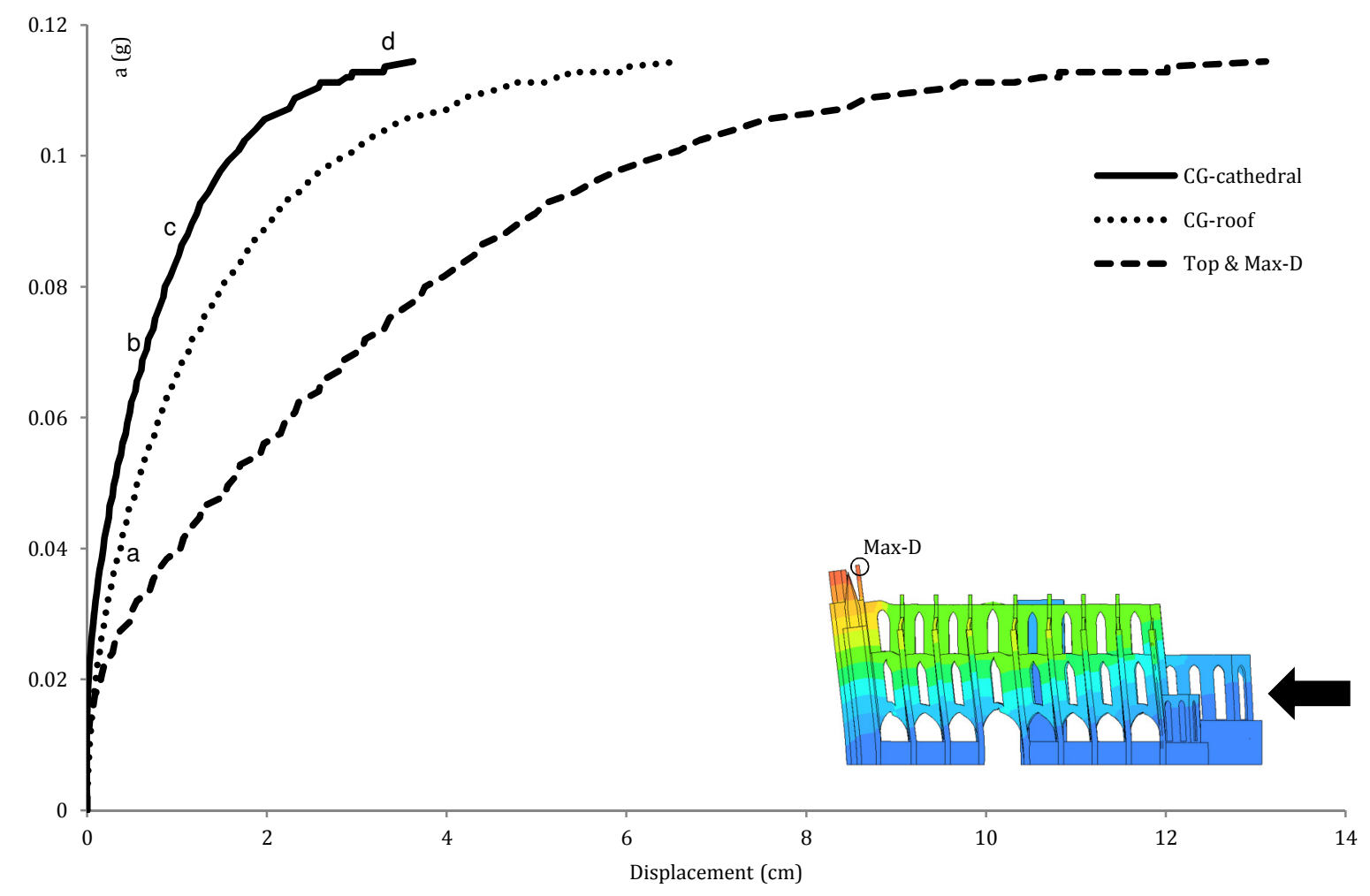

Figure 17. Capacity curve for the seismic analysis in $(+\mathrm{X})$ direction. The control point (Max-D) is shown in circle. 

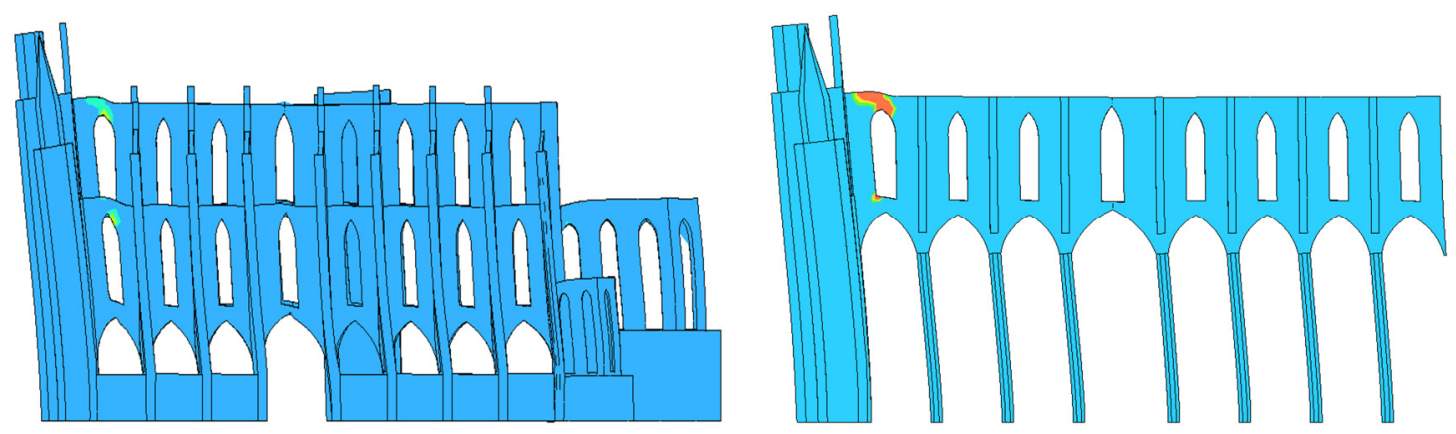

a) Crack initiation at $0,042 \mathrm{~g}$
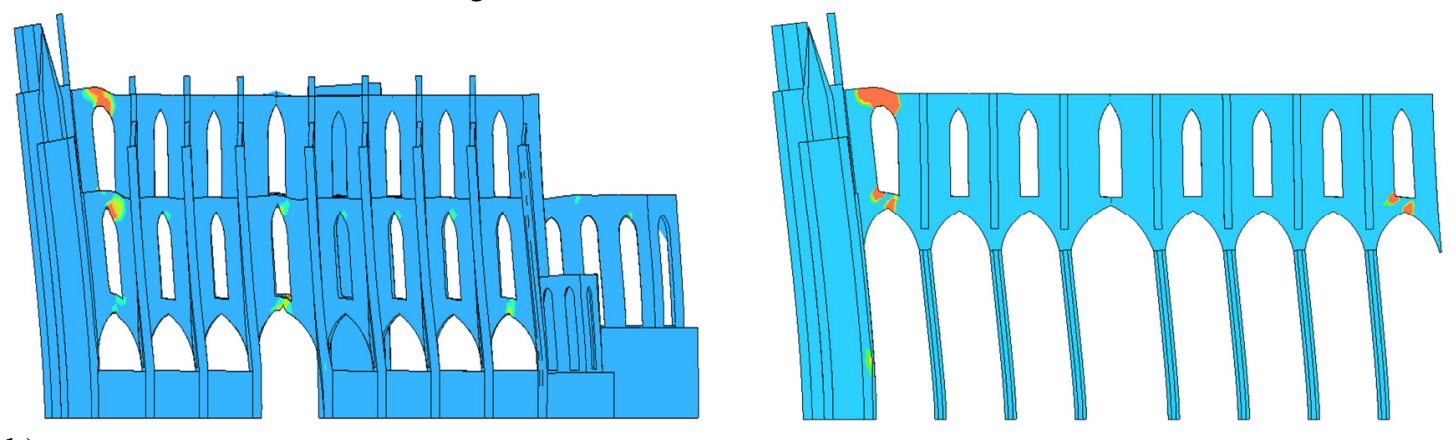

b) $\quad 0,070 \mathrm{~g}$
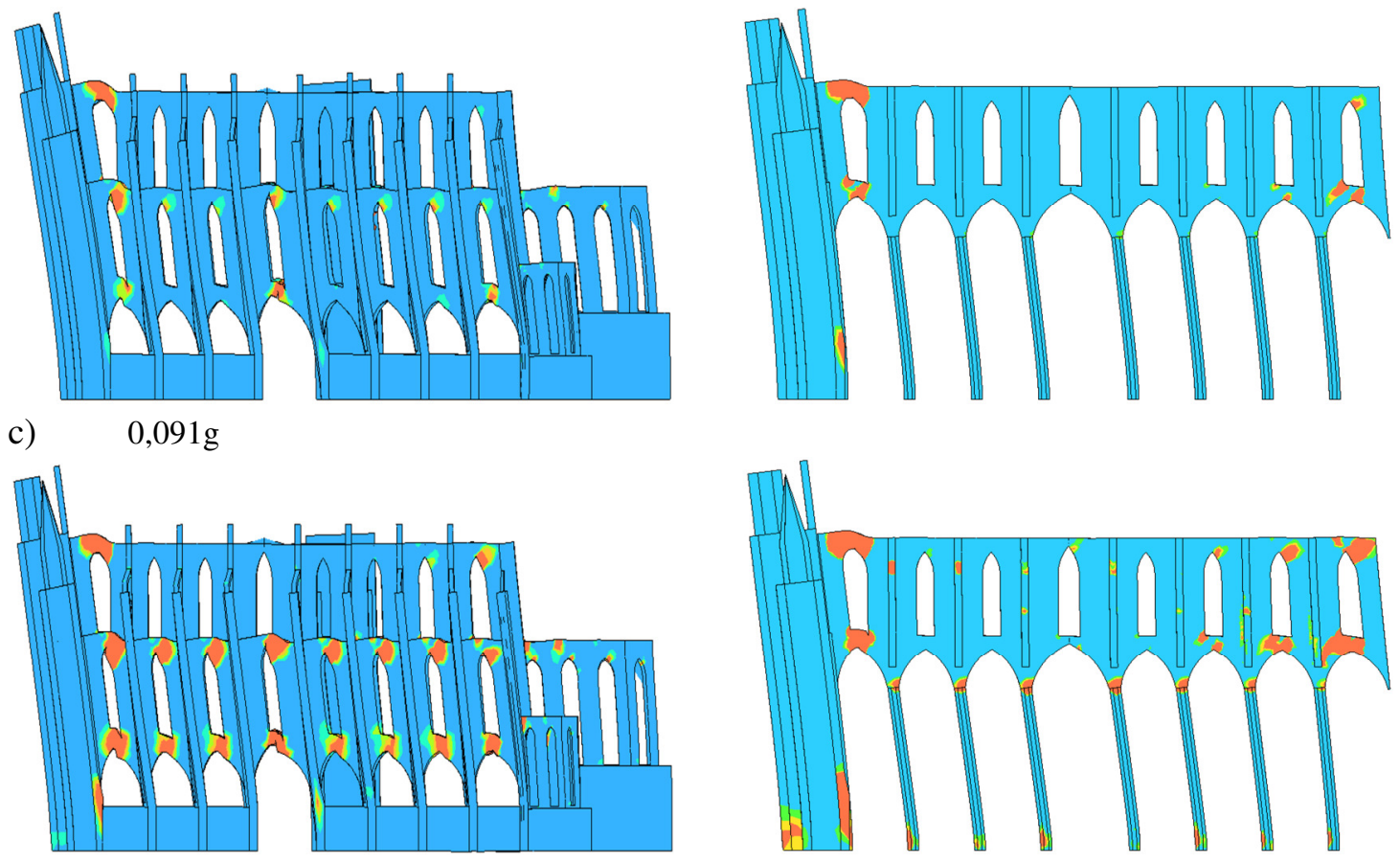

d) Collapse at $0,114 \mathrm{~g}$

Figure 18. Progress of damage in the two typical resisting frames: lower clerestory wall supported on buttresses (left); and upper clerestory wall supported on columns (right): (a) to (d) correspond to the points indicated in the capacity curve, Figure 17. Contour of maximum principal strain plotted on deformed mesh. Case of $(+X)$. 


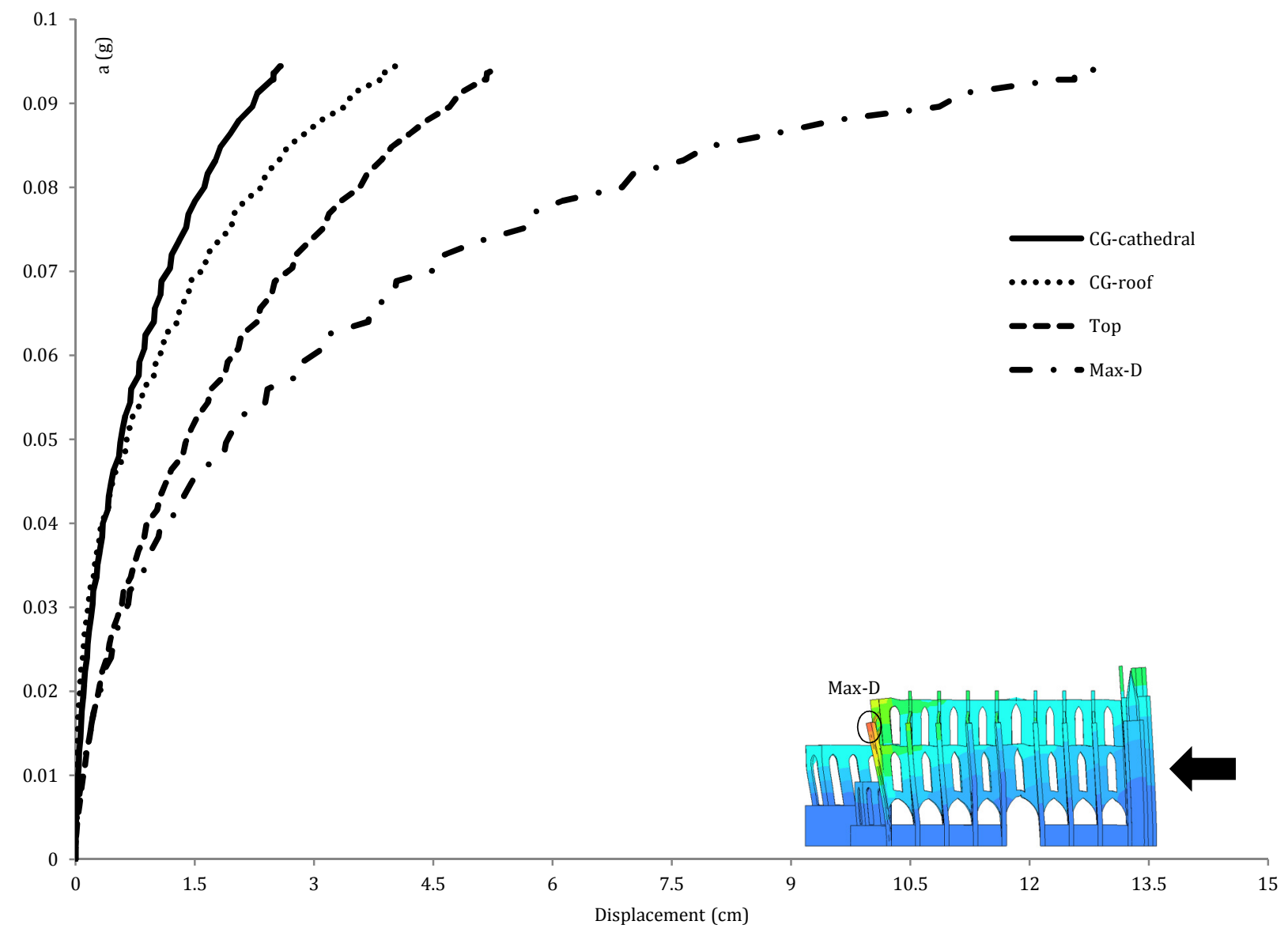

Figure 19. Capacity curve for the seismic analysis in (-X) direction. The control point (Max-D) is shown in circle. 


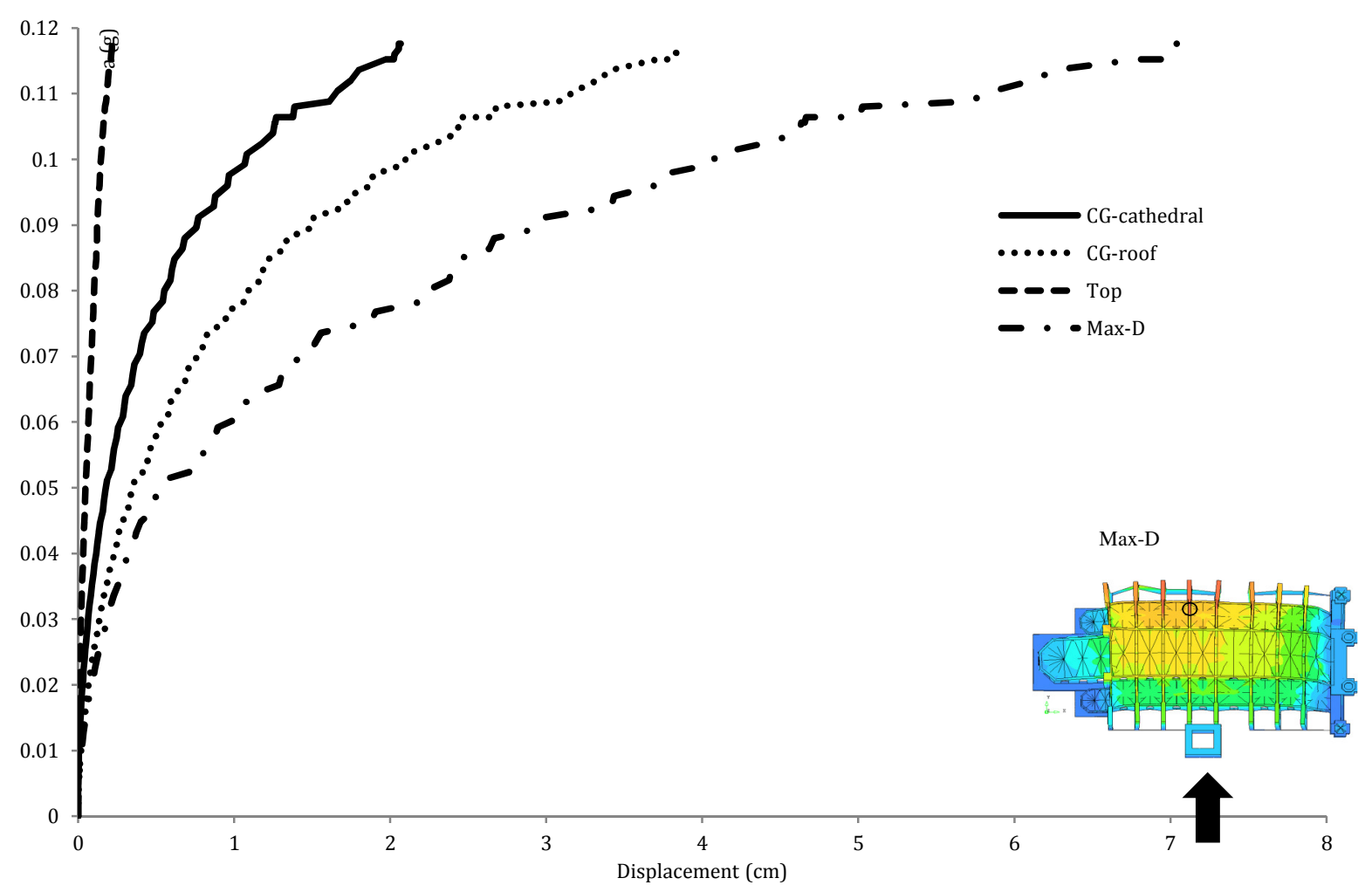

Figure 20. Capacity curve for the seismic analysis in (+Y) direction. The control point (Max-D) is shown in plan. 

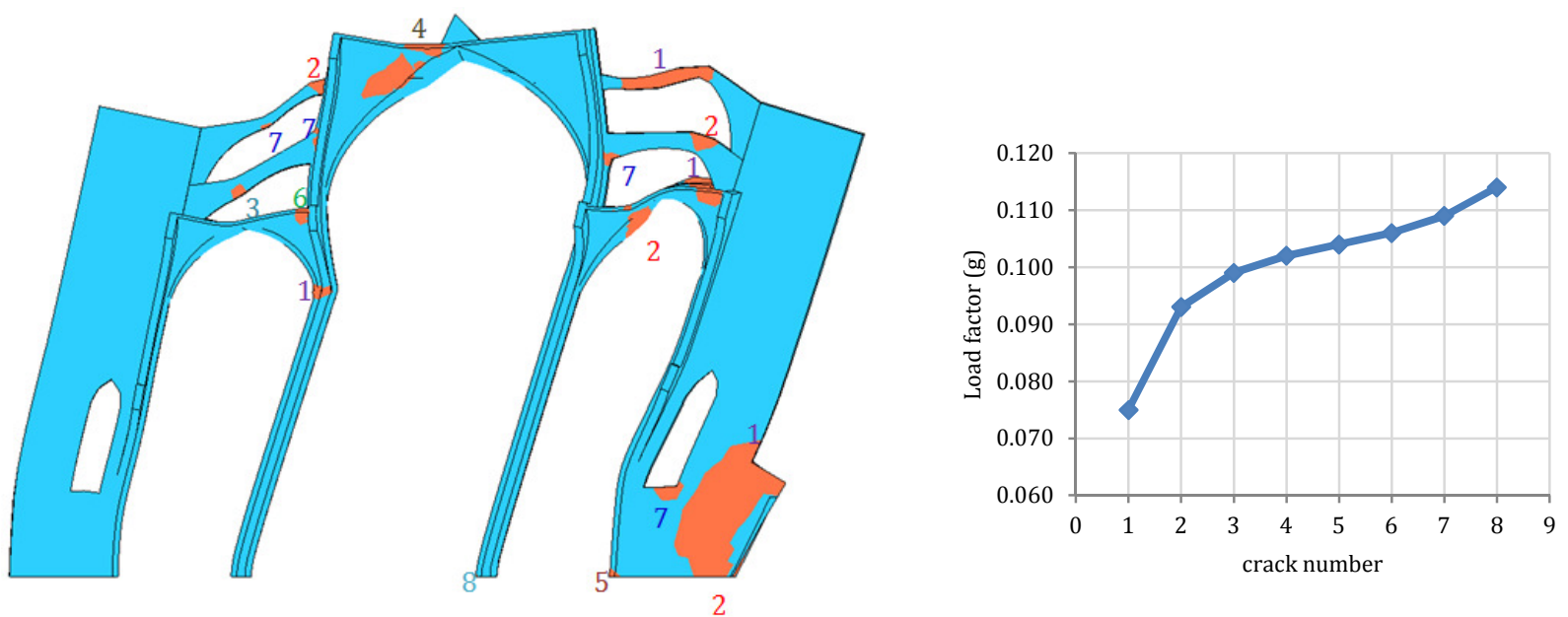

Figure 21. Cracking pattern at collapse with sequence of cracking (left); and the seismic load factor of initiation of each crack (right). 


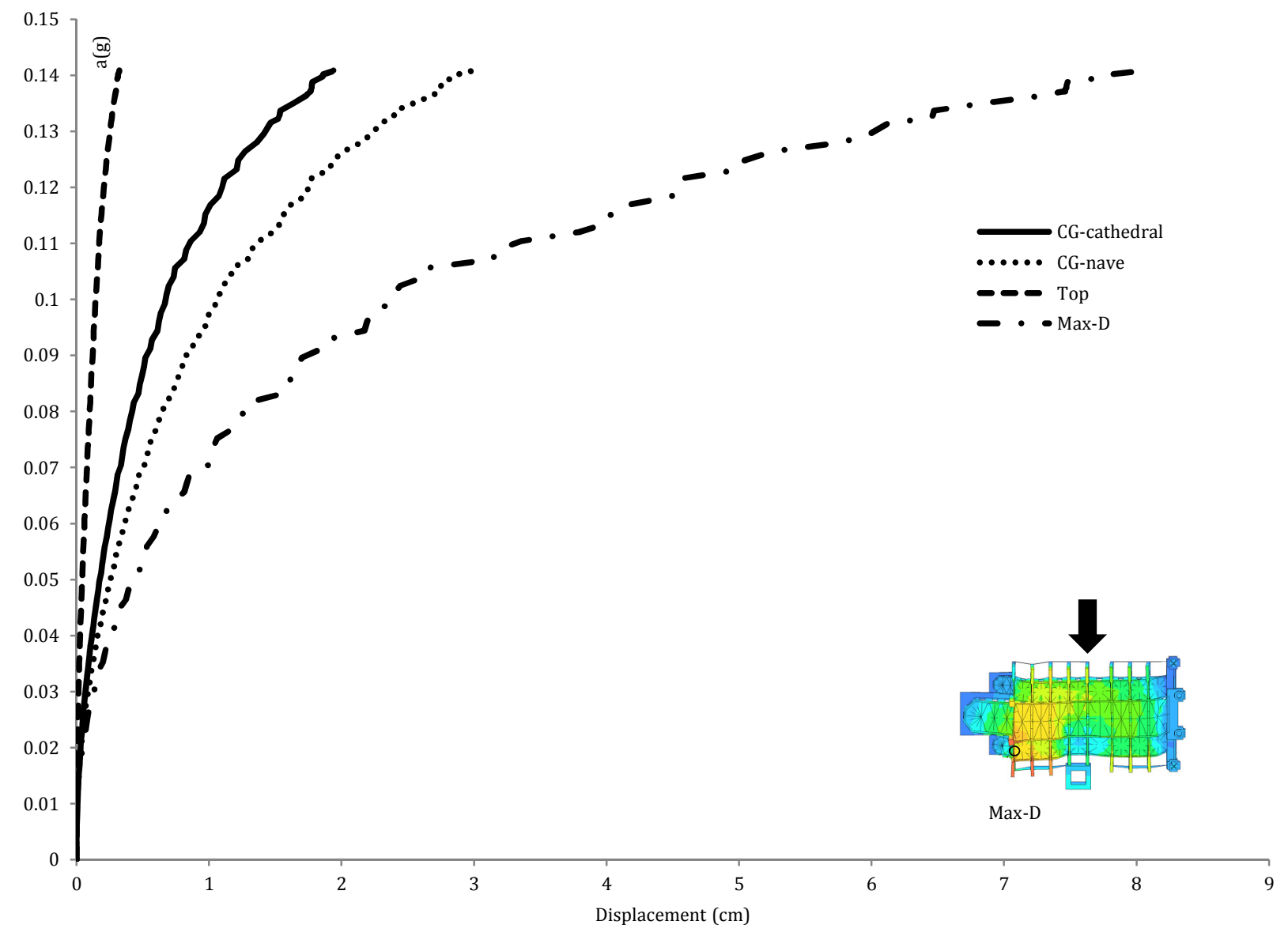

Figure 22. Capacity curve for the seismic analysis in (-Y) direction. The control point (Max-D) is shown in circle. 

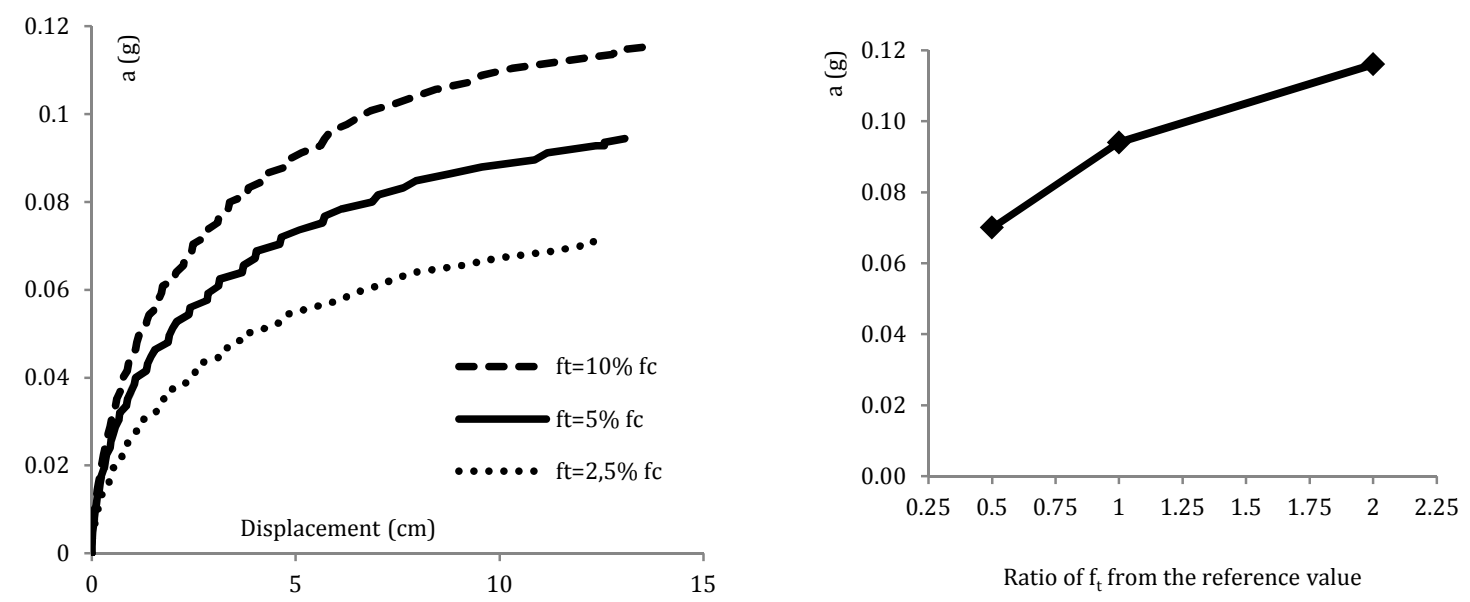

Figure 23. Capacity curves varying $f_{t}(l e f t)$; and change of the capacity with the change of $f_{t}$ ratio from the reference value (right). 

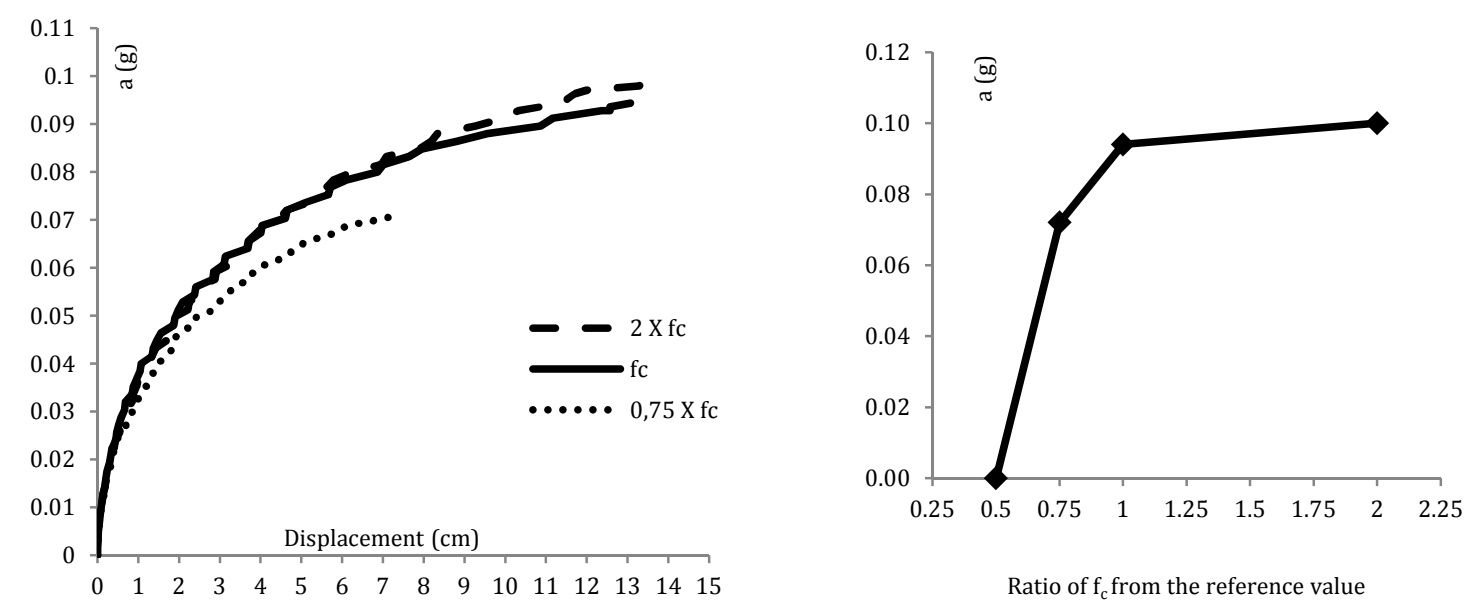

Figure 24. Capacity curves varying fc (Left); and change of the capacity with the change of fc ratio from the reference value (right). 

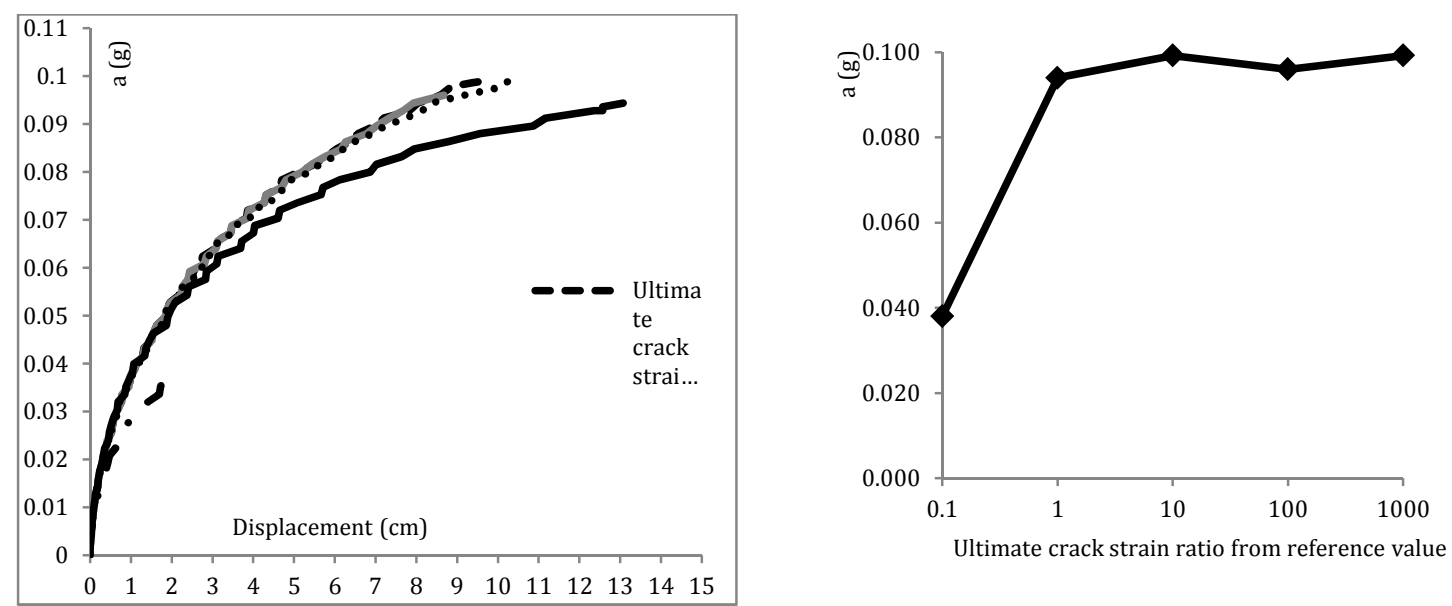

Figure 25. Capacity curves varying $\varepsilon_{u}^{c r}$ (left); and change of the capacity with the change of $\varepsilon_{u}^{c r}$ ratio from the reference value (right). 

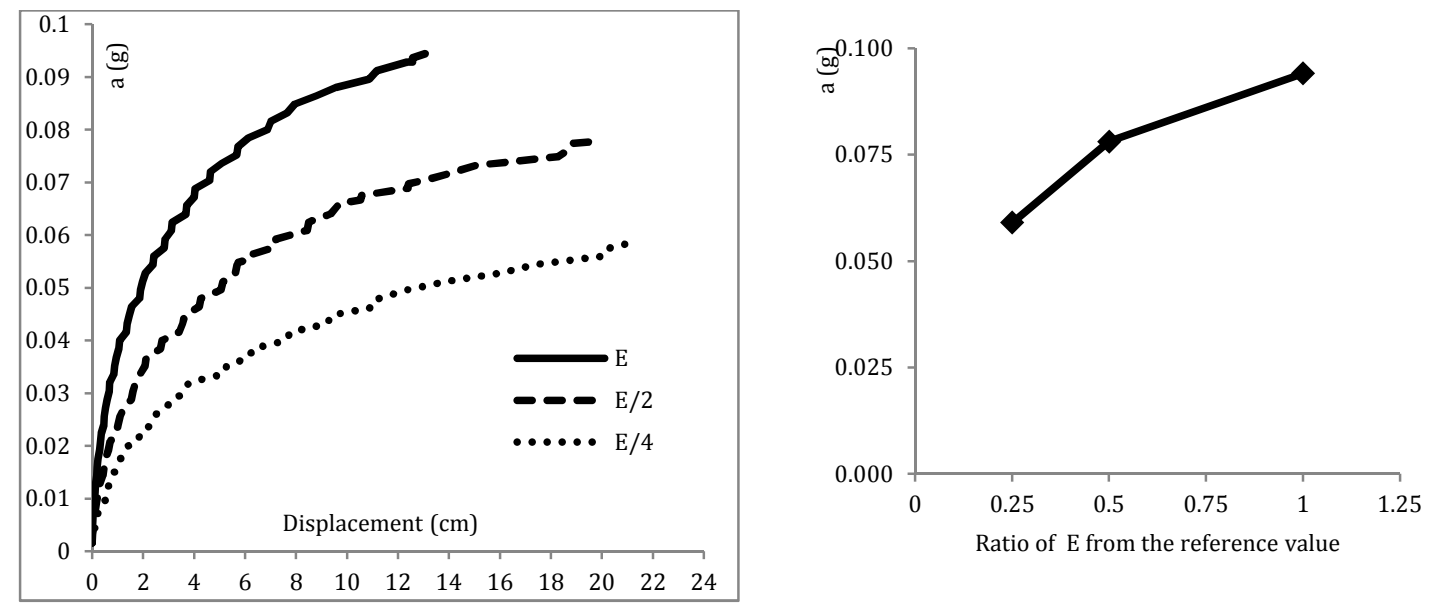

Figure 26. Capacity curves varying the modulus of elasticity E (left); and change of the capacity with the change of $\mathrm{E}$ ratio from the reference value (right). 


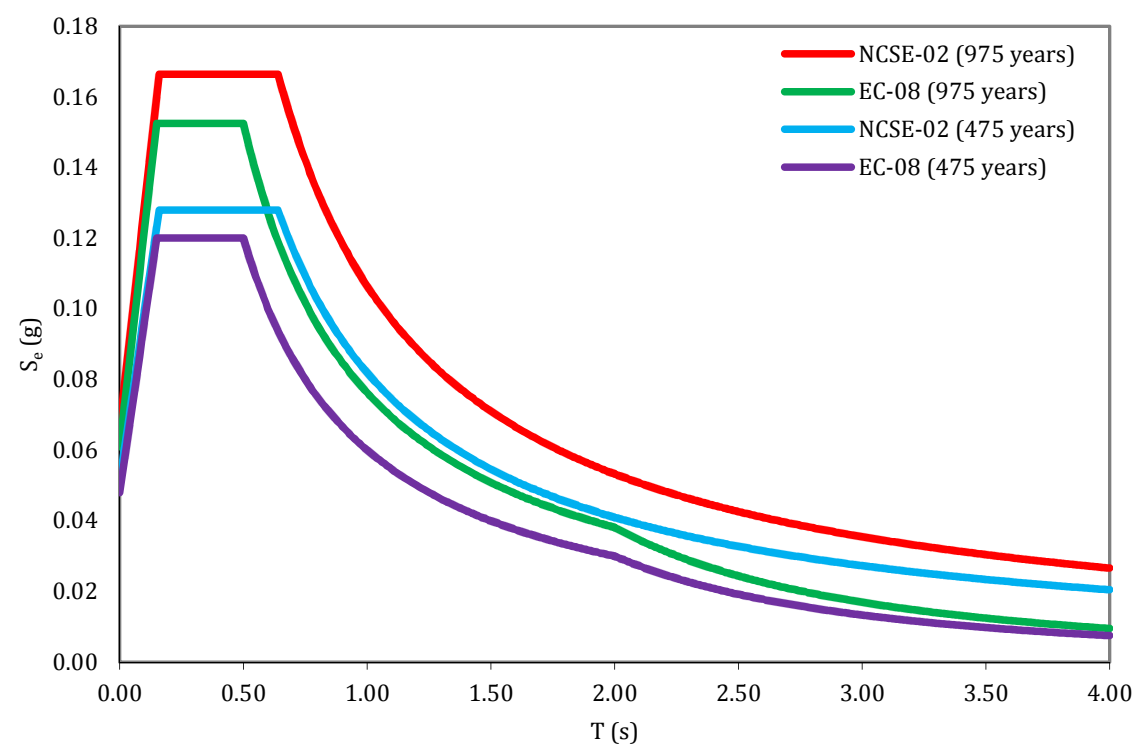

Figure 27. The elastic response spectrum Se (g) using the Eurocode 8 (EC8) and the Spanish code NCSE02. 


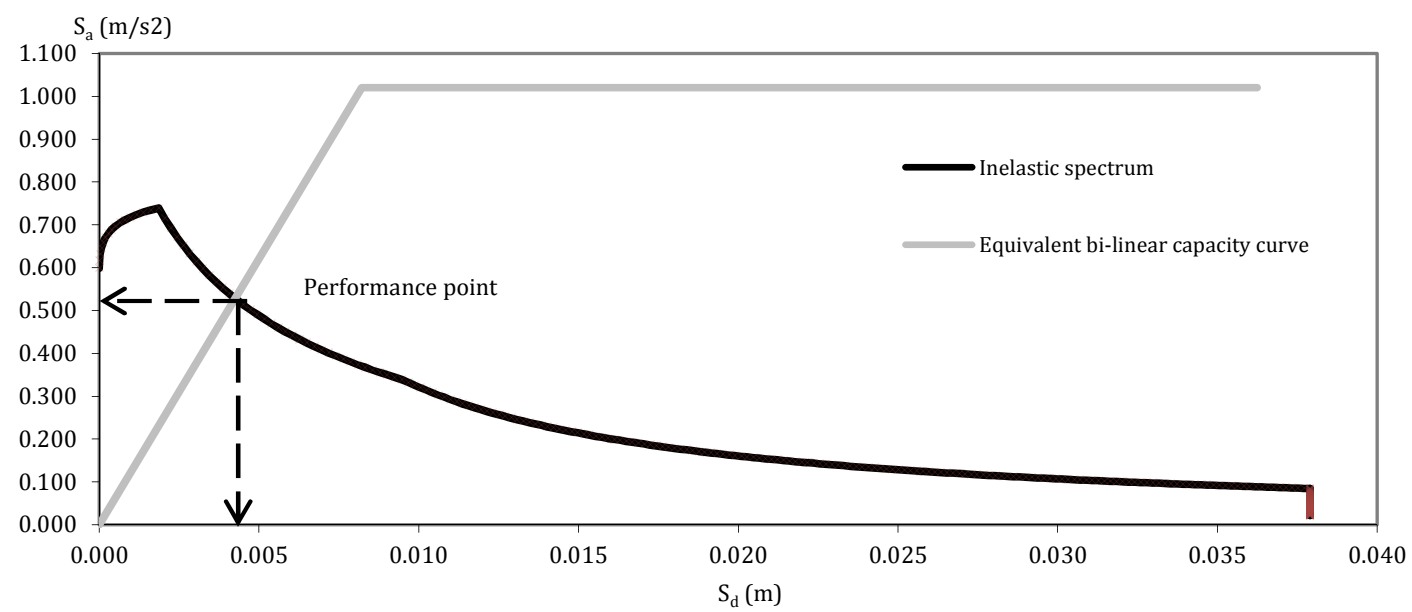

Figure 28. Application of the N2 method to the control point of CG-cathedral (case of $+X$ direction) and EC-08 (return period of 975 years) to find the performance point. 


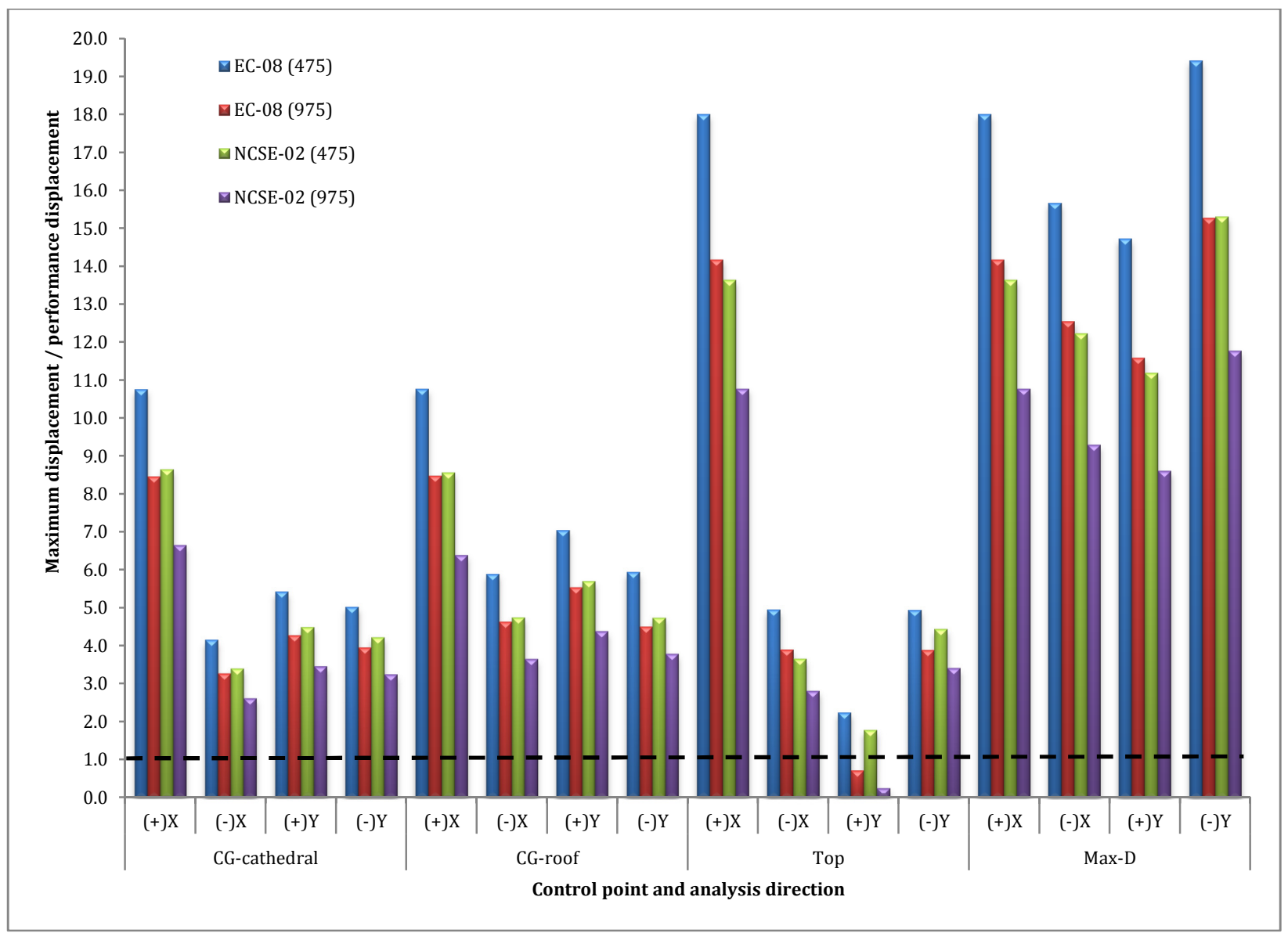

Figure 29. Evaluation of seismic safety in terms of displacements: ratios between maximum displacements and performance displacements. 


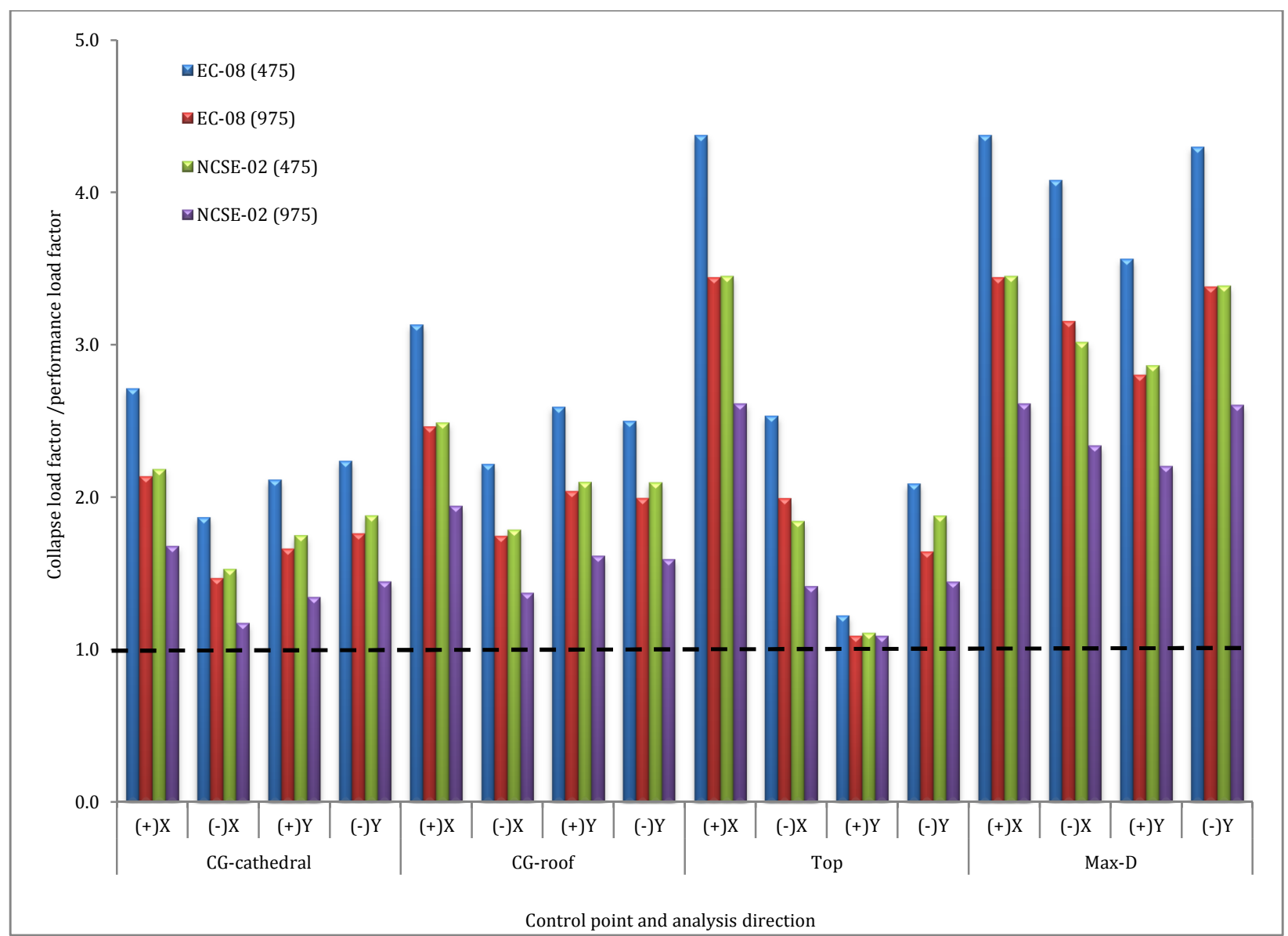

Figure 30. Evaluation of seismic safety in terms of load multipliers: ratios between collapse load multipliers and performance load multipliers. 
Table 1. Judgment of the quality of identification process of Mallorca cathedral. $\mathrm{P}=$ poor, $\mathrm{G}=$ good.

\begin{tabular}{lcccccccc}
\hline & \multicolumn{10}{c}{ Mode ID. } \\
\cline { 2 - 9 } Modal parameter & G & 2 & 3 & 4 & 5 & 6 & 7 & 8 \\
\hline Natural frequency & G & G & G & G & G & G & G & G \\
Damping ratio & P & G & G & G & P & P & P & P \\
Mode shape & P & G & G & G & P & P & P & P \\
\hline
\end{tabular}


Table 2. Properties of different materials in the FE model.

\begin{tabular}{llll}
\hline Structural parts & Young's Modulus $(\mathrm{MPa})$ & Density $\left(\mathrm{kg} / \mathrm{m}^{3}\right)$ & Poisson's ratio \\
\hline Walls and vaults & 3816 & 2100 & 0,2 \\
Buttresses & 3600 & 2100 & 0,2 \\
Columns and flying arches & 15264 & 2400 & 0,2 \\
Filling over the vaults & 1908 & 2000 & 0,2 \\
\hline
\end{tabular}


Table 3. Best correlated numerical and experimental modes and corresponding $D_{\mathrm{f}}$ and MAC values.

\begin{tabular}{lllllll}
\hline Numerical mode ID. & 1 & 2 & 5 & 8 & 9 & 10 \\
Frequency (Hz) & 1,270 & 1,592 & 1,924 & 2,269 & 2,414 & 2,638 \\
\hline Experimental mode ID. & 2 & 4 & 5 & 6 & 7 & 8 \\
Frequency (Hz) & 1,427 & 1,578 & 1,939 & 2,234 & 2,446 & 2,656 \\
\hline $\mathrm{D}_{\mathrm{f}}$ & 11,0 & 0,9 & 0,8 & 1,6 & 1,3 & 0,7 \\
MAC & 0,89 & 0,74 & 0,27 & 0,60 & 0,67 & 0,55 \\
\hline
\end{tabular}


Table 4. Comparing the numerical and experimental modes after each updating step.

\begin{tabular}{|c|c|c|c|c|c|c|c|}
\hline Step no. & Mode ID. & $\begin{array}{l}\text { 1Num- } \\
2 \mathrm{Exp}\end{array}$ & $\begin{array}{l}\text { 2Num- } \\
4 \mathrm{Exp}\end{array}$ & $\begin{array}{l}\text { 5Num- } \\
5 \mathrm{Exp}\end{array}$ & $\begin{array}{l}\text { 8Num- } \\
6 \mathrm{Exp}\end{array}$ & $\begin{array}{l}\text { 9Num- } \\
7 \mathrm{Exp}\end{array}$ & $\begin{array}{l}\text { 10Num- } \\
8 \mathrm{Exp}\end{array}$ \\
\hline \multirow{3}{*}{$\begin{array}{l}1 \\
\text { Longitudinal } \\
\text { wall }\end{array}$} & Num. Freq. (Hz) & 1,330 & 1,668 & 1,986 & 2,516 & 2,592 & 2,732 \\
\hline & $\mathrm{D}_{\mathrm{f}}$ & 6,8 & 5,7 & 2,4 & 12,6 & 7,4 & 2,9 \\
\hline & MAC & 0,89 & 0,71 & 0,24 & 0,30 & 0,80 & 0,55 \\
\hline \multirow{3}{*}{$\begin{array}{l}2 \\
\text { Chapels } \\
\text { vaults }\end{array}$} & Num. Freq. (Hz) & 1,422 & 1,682 & 2,016 & 2,556 & 2,611 & 2,764 \\
\hline & $D_{f}$ & 0,4 & 6,6 & 4,0 & 14,4 & 8,2 & 4,1 \\
\hline & MAC & 0,88 & 0,73 & 0,20 & 0,26 & 0,78 & 0,54 \\
\hline \multirow{3}{*}{$\begin{array}{l}3 \\
\text { Cathedral- } \\
\text { tower } \\
\text { connection }\end{array}$} & Num. Freq. (Hz) & 1,435 & 1,726 & 2,161 & 2,578 & 2,621 & 2,801 \\
\hline & $D_{f}$ & 0,5 & 9,4 & 11,4 & 15,4 & 8,6 & 5,5 \\
\hline & MAC & 0,89 & 0,74 & 0,13 & 0,15 & 0,80 & 0,53 \\
\hline \multirow{3}{*}{$\begin{array}{l}4 \\
\text { Buttresses } \\
\text { modulus of } \\
\text { elasticity }\end{array}$} & Num. Freq. (Hz) & 1,404 & 1,611 & 1,974 & 2,478 & 2,569 & 2,669 \\
\hline & $D_{f}$ & 1,6 & 2,1 & 1,8 & 10,9 & 6,4 & 0,5 \\
\hline & MAC & 0,88 & 0,75 & 0,16 & 0,29 & 0,77 & 0,54 \\
\hline \multirow{3}{*}{$\begin{array}{l}5 \\
\text { Elastic } \\
\text { foundations }\end{array}$} & Num. Freq. (Hz) & 1,399 & 1,577 & 1,950 & 2,464 & 2,562 & 2,645 \\
\hline & $D_{f}$ & 1,9 & 0,1 & 0,6 & 10,3 & 4,7 & 0,4 \\
\hline & MAC & 0,89 & 0,75 & 0,11 & 0,29 & 0,77 & 0,54 \\
\hline
\end{tabular}


Table 5. Used properties of the different materials in the FE model for the seismic assessment.

\begin{tabular}{ccccc}
\hline $\begin{array}{c}\text { Material No. \& } \\
\text { structural } \\
\text { elements }\end{array}$ & $\begin{array}{c}\text { (1) All the cathedral } \\
\text { except the following }\end{array}$ & (2) Buttresses & $\begin{array}{c}\text { (3) Columns and } \\
\text { flying arches }\end{array}$ & $\begin{array}{c}\text { (4)Filling over } \\
\text { vaults }\end{array}$ \\
\hline $\mathrm{f}_{\mathrm{c}}(\mathrm{MPa})$ & 2 & 2 & 8 & 1 \\
$\varepsilon_{u}^{c r}(\%)$ & 0,40 & 0,43 & 0,10 & 0,81 \\
\hline
\end{tabular}


Table 6. Chosen values for the sensitivity analysis*.

\begin{tabular}{lll} 
The variable & Minimum & Maximum \\
\hline Tensile strength $\left(\mathrm{f}_{\mathrm{t}}\right)$ & $\mathrm{f}_{\mathrm{t}}=2,5 \% \mathrm{f}_{\mathrm{c}}$ & $\mathrm{f}_{\mathrm{t}}=10 \% \mathrm{f}_{\mathrm{c}}$ \\
Compressive strength $\left(\mathrm{f}_{\mathrm{c}}\right)$ & $0,75 \times \mathrm{f}_{\mathrm{c}}$ & $2 \times \mathrm{f}_{\mathrm{c}}$ \\
Ultimate crack strain $\left(\varepsilon_{u}^{c r}\right)$ & $\varepsilon_{u}^{c r} / 10$ & $\varepsilon_{u}^{c r} \times 1000$ \\
modulus of elasticity $(\mathrm{E})$ & $\mathrm{E} / 4$ & $\mathrm{E} / 2$ \\
\hline \multicolumn{2}{c}{$*$ Refer to Table 2 and Table 5for the reference values express }
\end{tabular}

* Refer to Table 2 and Table 5for the reference values expressed here as symbols. 
Table 7. The performance displacements Dp (cm) and the performance load multiplier LMp (a $(\mathrm{g}))$ for the different control points.

\begin{tabular}{|c|c|c|c|c|c|c|c|c|c|}
\hline \multirow{2}{*}{$\begin{array}{l}\text { Analysis } \\
\text { Direction }\end{array}$} & \multirow{2}{*}{$\begin{array}{l}\text { Code (return } \\
\text { period, years) }\end{array}$} & \multicolumn{2}{|c|}{ CG-cathedral } & \multicolumn{2}{|c|}{ CG-roof } & \multicolumn{2}{|c|}{ Top } & \multicolumn{2}{|c|}{ Max-D } \\
\hline & & $\mathrm{D}_{\mathrm{p}}$ & $\mathrm{LM}_{\mathrm{p}}$ & $\mathrm{D}_{\mathrm{p}}$ & $\mathrm{LM}_{\mathrm{p}}$ & $\mathrm{D}_{\mathrm{p}}$ & $\mathrm{LM}_{\mathrm{p}}$ & $\mathrm{D}_{\mathrm{p}}$ & $\mathrm{LM}_{\mathrm{p}}$ \\
\hline \multirow[t]{4}{*}{$+\mathrm{X}$} & EC-08 (475) & 0.3 & 0.042 & 0.6 & 0.037 & 0.7 & 0.026 & 0.7 & 0.026 \\
\hline & EC-08 (975) & 0.4 & 0.054 & 0.8 & 0.046 & 0.9 & 0.033 & 0.9 & 0.033 \\
\hline & NCSE-02 (475) & 0.4 & 0.052 & 0.8 & 0.046 & 1.0 & 0.033 & 1.0 & 0.033 \\
\hline & NCSE-02 (975) & 0.5 & 0.068 & 1.0 & 0.059 & 1.2 & 0.044 & 1.2 & 0.044 \\
\hline \multirow[t]{4}{*}{$-\mathrm{X}$} & EC-08 (475) & 0.6 & 0.051 & 0.7 & 0.043 & 1.1 & 0.037 & 0.8 & 0.023 \\
\hline & EC-08 (975) & 0.8 & 0.064 & 0.9 & 0.054 & 1.4 & 0.047 & 1.0 & 0.030 \\
\hline & NCSE-02 (475) & 0.8 & 0.062 & 0.9 & 0.053 & 1.5 & 0.051 & 1.1 & 0.031 \\
\hline & NCSE-02 (975) & 1.0 & 0.080 & 1.1 & 0.069 & 1.9 & 0.067 & 1.4 & 0.040 \\
\hline \multirow[t]{4}{*}{$+\mathrm{Y}$} & EC-08 (475) & 0.4 & 0.056 & 0.6 & 0.045 & 0.1 & 0.096 & 0.5 & 0.033 \\
\hline & EC-08 (975) & 0.5 & 0.071 & 0.7 & 0.058 & 0.3 & 0.108 & 0.6 & 0.042 \\
\hline & NCSE-02 (475) & 0.5 & 0.067 & 0.7 & 0.056 & 0.1 & 0.106 & 0.6 & 0.041 \\
\hline & NCSE-02 (975) & 0.6 & 0.087 & 0.9 & 0.073 & 0.9 & 0.108 & 0.8 & 0.053 \\
\hline \multirow[t]{4}{*}{$-\mathrm{Y}$} & EC-08 (475) & 0.4 & 0.063 & 0.5 & 0.056 & 0.1 & 0.068 & 0.4 & 0.033 \\
\hline & EC-08 (975) & 0.5 & 0.080 & 0.7 & 0.071 & 0.1 & 0.086 & 0.5 & 0.042 \\
\hline & NCSE-02 (475) & 0.5 & 0.075 & 0.6 & 0.067 & 0.1 & 0.075 & 0.5 & 0.042 \\
\hline & NCSE-02 (975) & 0.6 & 0.097 & 0.8 & 0.088 & 0.1 & 0.098 & 0.7 & 0.054 \\
\hline
\end{tabular}

